\title{
Neuropathological Characterization of Dolphin Morbillivirus Infection in Cetaceans Stranded in Italy
}

\author{
Federica Giorda ${ }^{1,2, *(D)}$, Paola Crociara ${ }^{1,3}$, Barbara Iulini ${ }^{1}$, Paola Gazzuola ${ }^{1}$, Alessandra Favole ${ }^{1}$ (D), Maria Goria ${ }^{1}$, \\ Laura Serracca ${ }^{1}$, Alessandro Dondo ${ }^{1}$, Maria Ines Crescio 1, Tania Audino 1, Simone Peletto ${ }^{1}$ (D, \\ Cristina Esmeralda Di Francesco ${ }^{4}$ (D), Maria Caramelli ${ }^{1}$, Eva Sierra ${ }^{2}$ (D), Fabio Di Nocera ${ }^{5}$, Giuseppe Lucifora ${ }^{5}$,

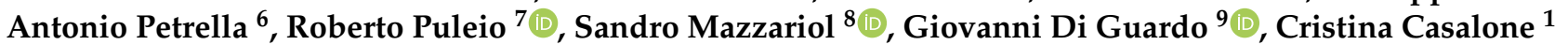 \\ and Carla Grattarola 1
}

check for updates

Citation: Giorda, F.; Crociara, P.; Iulini, B.; Gazzuola, P.; Favole, A.; Goria, M.; Serracca, L.; Dondo, A.; Crescio, M.I.; Audino, T.; et al. Neuropathological Characterization of Dolphin Morbillivirus Infection in Cetaceans Stranded in Italy. Animals 2022, 12, 452. https://doi.org/ 10.3390/ani12040452

Academic Editor: Øivind Bergh

Received: 30 December 2021

Accepted: 8 February 2022

Published: 12 February 2022

Publisher's Note: MDPI stays neutral with regard to jurisdictional claims in published maps and institutional affiliations.

Copyright: (C) 2022 by the authors. Licensee MDPI, Basel, Switzerland. This article is an open access article distributed under the terms and conditions of the Creative Commons Attribution (CC BY) license (https:// creativecommons.org/licenses/by/ $4.0 /)$.
1 Istituto Zooprofilattico Sperimentale del Piemonte, Liguria e Valle d'Aosta, 10154 Torino, Italy; paola.crociara@gmail.com (P.C.); barbara.iulini@izsto.it (B.I.); paola.gazzuola@izsto.it (P.G.); alessandra.favole@izsto.it (A.F.); maria.goria@izsto.it (M.G.); laura.serracca@izsto.it (L.S.); alessandro.dondo@izsto.it (A.D.); mariaines.crescio@izsto.it (M.I.C.); tania.audino@izsto.it (T.A.); simone.peletto@izsto.it (S.P.); maria.caramelli@izsto.it (M.C.); cristina.casalone@izsto.it (C.C.); carla.grattarola@izsto.it (C.G.)

2 Institute for Animal Health and Food Safety (IUSA), Faculty of Veterinary Medicine, University of Las Palmas de Gran Canaria, Las Palmas de Gran Canaria, 35416 Canary Islands, Spain; eva.sierra@ulpgc.es

3 Department of Prevention, Local Veterinary Services (ASLTO4), SS Sanità Animale, Piazza Gino Viano Bellandi, Cuorgnè, 10082 Torino, Italy

4 Faculty of Veterinary Medicine, University of Teramo, Strada Provinciale 18 Località Piano d'Accio, 64100 Teramo, Italy; cedifrancesco@unite.it

5 Istituto Zooprofilattico Sperimentale del Mezzogiorno, Via della Salute, 2, Portici, 80055 Napoli, Italy; fabio.dinocera@izsmportici.it (F.D.N.); giuseppe.lucifora@izsmportici.it (G.L.)

6 Istituto Zooprofilattico Sperimentale della Puglia e della Basilicata, Via Manfredonia 20, 71121 Foggia, Italy; antonio.petrella@izspb.it

7 Istituto Zooprofilattico Sperimentale della Sicilia, Via Gino Marinuzzi, 3, 90129 Palermo, Italy; roberto.puleio@izssicilia.it

8 Department of Comparative Biomedicine and Food Science, University of Padua, Legnaro, 35020 Padua, Italy; sandro.mazzariol@unipd.it

9 Retired Professor of General Pathology and Veterinary Pathophysiology, Veterinary Medical Faculty, University of Teramo, Localita' Piano d'Accio, 64100 Teramo, Italy; gdiguardo@unite.it

* Correspondence: federica.giorda@izsto.it

Simple Summary: There is abundant literature reporting demyelination in dogs and pinnipeds affected by morbillivirus infection, but myelinopathy is poorly investigated in stranded cetaceans affected with the virus. Also, the neuropathogenesis of cetacean morbillivirus infection has not been fully clarified, leaving questions on cell tropism unanswered. A novel dolphin morbillivirus lineage of Atlantic origin circulating in Italian waters replaced the previous Mediterranean strain in late 2015; however, differences in virulence and pathogenesis between the two strains have not yet been documented. The aims of the present study were to: describe histopathological changes and immunohistochemical findings in the central nervous system of 31 cetaceans which tested positive on molecular investigations for the two dolphin morbillivirus strains; characterize by double indirect immunofluorescence staining the areas of myelin damage. The most frequently observed morbillivirus-associated lesions were astro-microgliosis, neuronal necrosis, spongiosis, malacia, and non-suppurative meningoencephalitis. Demyelination was detected by means of a specific myelin biomarker. Inside and around the demyelinated areas there were morbillivirus antigen-bearing cells of mainly neuronal and microglial origin, associated with marked astro and microglia reactivity. Molecular and immunohistochemical analysis suggested a higher neurotropic affinity of the novel circulating strain.

Abstract: Cetacean morbillivirus (CeMV) is responsible for epidemic and endemic fatalities in freeranging cetaceans. Neuro-inflammation sustained by CeMV is a leading cause of death in stranded cetaceans. A novel dolphin morbillivirus (DMV) strain of Atlantic origin circulating in Italian waters 
since early 2016 has caused acute/subacute lesions associated with positive immunolabelling of the virus. To date, myelin damage has not been fully documented and investigated in cetaceans. This study describes neuropathological findings in the brain tissue of 31 cetaceans found stranded along the Italian coastline and positive for DMV infection on molecular testing. Cell changes in the areas of myelinopathy were revealed by double indirect immunofluorescence. The most frequent DMV-associated lesions were astro-microgliosis, neuronal necrosis, spongiosis, malacia, and non-suppurative meningoencephalitis. Myelin reduction and areas of demyelination were revealed by means of a specific myelin biomarker. Morbilliviral antigen immunolabelling was mainly observed in neurons and microglial cells, in association with a marked activation of microglia and astrocytes. These findings extend our knowledge of DMV-associated brain lesions and shed light on their pathogenesis.

Keywords: cetacean morbillivirus; cetaceans; meningoencephalitis; demyelination; neuropathology; immunofluorescence

\section{Introduction}

Neuro-inflammation is a leading cause of death in stranded cetaceans, in which the brain is found to be the only organ affected in some cases [1-3]. Viral meningoencephalitis sustained by cetacean morbillivirus (CeMV) is the most frequent form of meningoencephalitis in cetaceans [2,3]. A member of the genus Morbillivirus (family Paramyxoviridae, subfamily Orthoparamyxovirinae), CeMV is the natural agent with the greatest impact on cetacean health and conservation worldwide [4]. This non-segmented single-stranded RNA virus includes three well-characterized strains: dolphin morbillivirus (DMV), porpoise morbillivirus, and pilot whale morbillivirus, plus four more strains recently identified in Hawaii and the southern hemisphere [5-8].

Genomic studies on DMV sequences circulating in the Mediterranean basin in the last 30 years show that the strain is generally well conserved $[9,10]$. In the last 6 years, however, the DMV Mediterranean strain has been substituted by a new variant called DMV northeast (NE)-Atlantic strain originating from the coasts of Galicia and Portugal [10-12]. No difference in virulence and disease severity between the two strains has been confirmed to date [4].

Neuropathological changes due to morbillivirus infection include demyelination, which is largely reported in both marine and terrestrial species and is commonly associated with canine and phocine distemper virus infection [13-16]. Few studies have described myelin changes in cetaceans with CeMV infection to date [12,17-19]. In some cases, infection has been confirmed by Luxol Fast Blue staining, which has not always proven effective in showing demyelination, however [20].

With the present study, we describe the histopathological changes in the central nervous system (CNS) of cetaceans with DMV infection found stranded along the Italian coastline in the period 2008-2020. In addition, we document differences in the virulence of the two strains circulating in the Mediterranean Sea.

To do this, we performed neuropathological characterization of areas of demyelination/hypomyelination by means of double indirect immunofluorescence (IF) staining to reveal cell changes and viral colonization of the neuronal and glial cell populations. Myelinopathy was confirmed by successful IF staining. To the best of our knowledge, this is the first study on neuropathological characterization by means of double IF staining in marine mammals with systemic CeMV infection. In addition, it is the first application of confocal laser-scanning microscopy for in-depth analysis of CeMV infection. 


\section{Materials and Methods}

\subsection{Materials}

All animals were stranded cetaceans diagnosed during routine pathological analysis and cause-of-death assessment by the Italian cetacean stranding network, Istituti Zooprofilattici Sperimentali, veterinary public health institutions under the Italian Ministry of Health. The animals were examined and submitted to complete post mortem examination according to standard protocols [21].

Epidemiological (stranding location and date) and biological data (species, sex, age class, nutritional and decomposition status) were recorded. The animals were divided into three age categories (newborn-calf, juvenile-subadult, adult) based on total body length [21,22]. The decomposition condition of the carcasses (DCC) was classified as: code 1 (extremely fresh carcass, just died); code 2 (fresh); code 3 (moderate decomposition); code 4 (advanced decomposition); and code 5 (mummified or skeletal remains) [23]. The nutritional condition state (NCC) was classified as good, moderate or poor based morphologically on anatomical parameters (e.g., convexity of dorsal profile, rib prominence, amount of body fat).

During necropsy, tissue samples from major organs were collected and divided into three aliquots for subsequent analysis: one was kept frozen at $-20{ }^{\circ} \mathrm{C}$ for microbiological analysis, one at $-80{ }^{\circ} \mathrm{C}$ for biomolecular analysis, and the third was preserved for 10 to 14 days in neutral buffered formalin for histological and immunohistochemical (IHC) analysis. When available, ten areas of the CNS were sampled and examined: basal nuclei, thalamus, mesencephalon, pons, obex, spinal cord, and frontal, parietal, occipital, and cerebellar cortex. After fixing in $10 \%$ neutral buffered formalin, the tissue samples were embedded in paraffin, cut to $4 \pm 2 \mu \mathrm{m}$ thick, stained with haematoxylin and eosin (H\&E), and examined under a light microscope.

Serological testing to screen for specific antibodies against morbillivirus and T. gondii was performed on serum, cerebrospinal fluid (CSF), and aqueous humour kept frozen at $-20{ }^{\circ} \mathrm{C}$, when available. The samples were tested by rapid serum agglutination (Rose Bengal plate test, RBT) using RBT antigen produced from B. abortus strain S99 [24,25] to detect anti-smooth Brucella spp. antibodies.

\subsection{Neuropathological Investigation}

The neuropathological reports of 188 brain samples submitted to the Italian National Reference Center for Diagnostic Activities in Stranded Marine Mammals (Centro di Referenza Nazionale per le Indagini Diagnostiche sui Mammiferi marini spiaggiati, C.Re.Di.Ma.) in the period 2007-2020 (69/188 in 2007-2015 and 119/188 in 2016-2020) were retrieved and further analysed for biomolecular investigation of DMV on the samples.

Morbillivirus IHC was carried out on tissue sections from all 188 CNS samples by means of a monoclonal anti-canine distemper virus (CDV) antibody (VMRD, Pullman, WA, USA) [25]. T. gondii IHC was carried out by means of a polyclonal serum of caprine origin (VMRD) on the tissue samples that showed microscopic and/or molecular evidence of protozoan infection [25].

In all, 31 animals had a morphological diagnosis of CNS inflammation or showed neurodegenerative and reactive changes referable to morbillivirus infection; 37 tested positive for DMV on PCR assay (9/37 were positive for the DMV Mediterranean variant and 28/37 for the DMV NE-Atlantic variant) [10]. Six animals were excluded: 3 were not evaluable due to advanced post mortem autolysis and 3 others presented no evidence of microscopic lesions. Only 9/66 animals (13\%) resulted positive on molecular testing for DMV (Mediterranean variant) between 2007 and 2015, whereas 28/119 (23\%) tested positive for DMV (NE-Atlantic variant) between 2016 and 2020.

Necropsy reports, including biological and epidemiological data, photographic material, and results of ancillary investigations of the 31 animals were retrieved and further analysed for assessment of the cases and determination of co-infection with other bacterial or viral neurotropic agents. A few cases were also previously published [1,10,12,26-30]. 
For the present study, the cerebral and the cerebellar cortex (because always present in the sample set) were re-examined according to the scheme devised by Sierra and colleagues (2020) [2] and slightly modified according to the description of CNS lesions reported in dogs affected by CDV [14,31]. Two independent pathologists scored the severity of meningitis, perivascular cuffing, astro-microgliosis, malacia, neuronal necrosis, and spongiosis as absent $(-)$, minimal $(+)$, mild $(++)$, moderate $(+++)$, and severe $(++++)$; intranuclear and/or intracytoplasmic inclusion bodies (INCIBs), haemorrhage, and IHC labelling for morbillivirus were scored as absent $(-)$ or present $(+)$. The stage of infection, termed acute $(A)$, subacute $(S)$ or chronic $(C)$, was determined by multiparametric assessment of the type of neuropathological changes, antigen detection, and presence of co-infection [2,20,31,32]. Lesions of other anatomical regions and non-CNS lesions were recorded when present.

Three animals classified as DCC 2 (fresh carcass, well-preserved tissues), without co-infection with other bacterial and viral neurotropic pathogens, but presenting severe myelinopathy (ID 9, ID 10, ID 28) and brain immunolabelling for CDV were selected for further analysis by double staining indirect immunofluorescence (IF). The aim was to reveal myelin changes and characterize the brain cell populations targeted by the virus involved in demyelinated/hypomyelinated areas in DMV infection.

To do this, selected formalin-fixed paraffin-embedded (FFPE) tissues $4 \pm 2 \mu \mathrm{m}$ thick (cerebral cortex for ID 9; cerebellar cortex for ID 10; cerebral and cerebellar cortex for ID 28) characterized by severe spongiosis in white matter were processed for IF analysis. Negative control tissues consisting of FFPE cerebral and cerebellar cortex samples from a striped dolphin in DCC 2 tested negative on analysis (molecular, IHC, microbiological) for other neurotropic agents, e.g., DMV, herpesvirus (HV), T. gondii, and Brucella spp., without evidence of neuropathological changes.

In detail, antigen retrieval was performed using $10 \mathrm{mM}$ citrate buffer ( $\mathrm{pH}$ 6.1) at $95^{\circ} \mathrm{C}$ for $20 \mathrm{~min}$. Sections were incubated in blocking buffer (5\% normal donkey serum, $0.3 \%$ Triton $\mathrm{X}-100$ in $0.01 \mathrm{M}$ PBS, $\mathrm{pH} 7.4$ ) for $1 \mathrm{~h}$ at room temperature, then incubated for $24-48 \mathrm{~h}$ at $4{ }^{\circ} \mathrm{C}$ in a solution of $0.01 \mathrm{M} \mathrm{PBS}, \mathrm{pH} 7.4$, containing $0.1 \%$ Triton X-100, $2 \%$ normal donkey serum, and the primary antibodies. Commercially available primary antibodies (Abs) were used: murine monoclonal anti-CDV (1:500, VMRD Inc, Pullman, WA, USA), rabbit polyclonal (poAb) anti-GFAP (1:1000; Millipore, Burlington, MA, USA) (astrocytic marker), rabbit poAb anti-Iba 1 (1:1000, Wako Chemicals Corp., Osaka, Japan) (microglia marker), rabbit poAb anti-oligodendrocyte transcription factor (Olig2) (1:250, Millipore) (oligodendrocyte marker), rabbit poAb anti-myelin proteolipid protein (PLP) (1:500, Abcam, Cambridge, MA, USA) (myelin marker), and a rabbit poAb anti-NeuN (1:1000 Abcam) (neuron marker). After several washes, the sections were incubated with appropriate solutions of donkey Alexa 488 or Alexa 555 conjugated secondary antibodies (1:1000, Thermo Fisher Scientific, Waltham, MA, USA). The slides were then washed in PBS, counterstained with 4,6-diamidino-2-phenylindole (DAPI, 1:1000, KPL, Gaithersburg, MD, USA) and mounted with Fluoromount G (SouthernBiotech, Birmingham, AL, USA). As negative internal controls, primary antibodies were eliminated and replaced by nonimmune homologous serum. All fluorescence images were captured on a confocal laser scanning microscope (Leica TCS SP8, Leica Microsystem, Wetzlar, Germany).

Since no results were obtained with the Ab anti-Olig2 in IF (see Results) dual IHC was attempted for simultaneous localization of CDV and Oligo2. Antigen retrieval was obtained using $10 \mathrm{mM}$ citrate buffer $\left(\mathrm{pH} \mathrm{6.1)}\right.$ ) at $95^{\circ} \mathrm{C}$ for $10 \mathrm{~min}$. The sections were immersed in $3 \%$ hydrogen peroxide solution in methanol for 20 min to block endogenous peroxidases and subsequently pretreated with 3\% normal horse serum in Tris-buffered saline with $0.1 \%$ Tween 20 detergent (TBST) for $20 \mathrm{~min}$. CDV immunohistochemistry was performed first using anti-CDV Ab (VMRD Inc, Pullman, WA, USA) diluted 1:500 in TBST at $4{ }^{\circ} \mathrm{C}$ overnight. The slides were treated with appropriate secondary antibody conjugated to biotin, then developed using avidin-conjugated horseradish peroxidase (VECTASTAIN ${ }^{\circledR}$ ABC-HRP Kit, Peroxidase-Mouse IgG, PK4002, Vector Laboratories, Burlingame, CA, USA) with DAB (K3467, Agilent Dako, Santa Clara, CA, USA) as substrate. The sections were 
then submitted to Oligo2 immunohistochemistry for testing the two markers: the rabbit poAb anti-Olig2 (1:250 Millipore, Burlington, MA, USA) and the rabbit monoclonal antiOlig2 Ab (1:100 Abcam, Cambridge, MA, USA) diluted in TBST and incubated at $4{ }^{\circ} \mathrm{C}$ overnight. Both anti-Oligo2 antibodies were revealed using the VECTASTAIN ${ }^{\circledR}$ ABC-HRP Kit, Peroxidase -Rabbit IgG (PK4001, Vector Laboratories, Burlingame, CA, USA) with peroxidase substrate VIP (SK-4600, Vector Laboratories, Burlingame, CA, USA). Table 1 presents the abs and their characteristics.

Table 1. Primary antibodies for neuropathological characterization in demyelinated/hypomyelinated areas by means of double IF and double IHC.

\begin{tabular}{ccccccc}
\hline Antigen & Target & $\begin{array}{c}\text { Antibody/ } \\
\text { Antiserum }\end{array}$ & Host & Dilution & Source & Technique(s) \\
\hline CDV-NP & Infected cells & Mono & Mouse & $1: 500$ & VMRD & IF, IHC \\
\hline GFAP & Astrocyte & Poly & Rabbit & $1: 1000$ & Millipore & IF \\
\hline Iba-1 & Microglia & Poly & Rabbit & $1: 1000$ & Wako & IF \\
\hline Myelin-PLP & Myelin & Poly & Rabbit & $1: 500$ & Abcam & IF \\
\hline NeuN & Neuron & Poly & Rabbit & $1: 1000$ & Abcam & IF \\
\hline Olig2 & Oligodendrocyte & Poly & Rabbit & $1: 250$ & Millipore & IF, IHC \\
\hline Olig2 & Oligodendrocyte & Mono & Rabbit & $1: 100$ & Abcam & IHC \\
\hline
\end{tabular}

Legend: CDV denotes canine distemper virus; NP nucleoprotein; PLP proteolipid protein; poly polyclonal; mono monoclonal; IF immunofluorescence; IHC immunohistochemistry.

Finally, anti-myelin, anti-GFAP, anti-NeuN, and anti-Iba1 abs were validated by means of Western blot assay for their use in striped dolphin brain samples (Supplementary Materials Figure S1).

\subsection{PCR and Sequence Analysis in CNS}

Molecular detection of dolphin morbillivirus (DMV) was achieved from a fresh-frozen sample of CNS (approximately $1 \mathrm{~g}$ ) consisting of several subsamples from different anatomical areas of the brain and the cerebellum. This was done to increase diagnostic sensitivitygiven the multifocal localization of the infection [32] - with an end-point RT-PCR using degenerate primers to amplify $287 \mathrm{bp}$ of the nucleoprotein $(\mathrm{N})$ gene [26].

All CNS samples $(n=31)$ were screened for other common neurotropic pathogens for cetaceans [1,2], including herpesvirus, T. gondii, and Brucella spp. In detail, herpesvirus detection was performed with a nested PCR using degenerate primers to amplify a region of the DNA polymerase gene [33]. T. gondii DNA was detected with a nested-PCR targeting the ITS1 region [34], and Brucella spp. with a TaqMan®Brucella species detection kit (Applied Biosystems, Foster City, CA, USA) for real-time PCR targeting the IS711 gene.

For DNA and RNA extraction, tissue samples (30-50 mg) were physically disrupted using a TissueLyser II homogenizer (Qiagen, Hilden, Germany) by high-speed shaking in plastic tubes with stainless-steel beads ( $5 \mathrm{~mm}$ diameter). Genomic DNA was then extracted from the disrupted tissues with an All-Prep DNA/RNA Mini kit (Qiagen, Hilden, Germany) according to the manufacturer's instructions.

The PCR products were analysed by electrophoresis on $2 \%$ agarose gel containing GelRed (Biotium, Fremont, CA, USA), compared with molecular weight markers, and then photographed on a Gel-Doc UV transilluminator system (Bio-Rad, Hercules, CA, USA).

For the DMV and herpesvirus assays, the amplicons were directly sequenced using PCR primers on a 3130XL Genetic Analyzer (Thermo Fisher Scientific Inc., Waltham, Massachusetts, USA). The sequences were aligned using SeqMan software (Lasergene package. DNASTAR Inc., Madison, WI, USA) to obtain a consensus sequence and compared with available sequences retrieved from the National Center for Biotechnology Information (NCBI) database with the BLAST tool (Available online: http://blast.ncbi.nlm.nih.gov/ Blast.cgi; accessed on 10 November 2021). Molecular characterization to discriminate between the DMV strains was carried out as described by Bellière and colleagues [35]. 


\subsection{Microbiological Analysis of the CNS: Standard and Specific for Brucella Isolation}

All CNS samples $(n=31)$ were processed for standard aerobic, anaerobic, and microaerobic $\left(5 \% \mathrm{CO}_{2}\right)$ bacterial culture and identification by biochemical and/or molecular analysis. Cultures for Brucella spp. were performed following international recommendations [36] and using selective and non-selective solid media and enrichment broths to enhance the chance of isolation.

\subsection{Statistical Analysis}

Statistical analyses were performed using STATA 17.1 (StataCorp College Station, Texas, USA). As most of the variables are ordinal, we performed univariate analysis with the non-parametric Wilcoxon-Mann-Whitney test to compare either the individual variable (sex, age class, species) or the score of the CNS lesions (meningitis, perivascular cuffing, astro-microgliosis, malacia, neuronal necrosis, spongiosis, intranuclear and/or intracytoplasmic inclusion bodies (INCIBs), haemorrhage, and stage of infection) or the molecular or the immunohistochemical findings between the two DMV strains. Statistical significance was set at $p<0.05$. Multivariate analysis was performed by means of multilevel mixed-effect logistic models, including the strain as the dependent variable, age class, and CNS lesion score, the molecular and the immunohistochemical findings as independent variables, and the individual animal as a random effect.

\section{Results}

We analysed 31 cetaceans with a microscopic diagnosis of brain inflammation or showing neurodegenerative and reactive changes associated with molecular confirmation of DMV infection: 29 striped dolphins (Stenella coeruleoalba Meyen, 1833) (93.5\%) and 2 bottlenose dolphins (Tursiops truncatus Montagu, 1821) (6.5\%).

History and stranding data are presented in Supplementary Materials Table S1. Males $(20 / 31 ; 64.5 \%)$ outnumbered females $(11 / 31 ; 35.5 \%)$. The majority were juvenilesubadults $(17 / 31 ; 54.8 \%)$ while the others were adults $(14 / 31 ; 45.2 \%)$; no calves/newborns were present.

Only $3 / 31$ carcasses $(9.7 \%)$ were classified as very fresh (DCC 1$)$, most were fresh $(20 / 31 ; 64.5 \%)$ (DCC 2$)$ and $8 / 31(25.8 \%)$ were moderately decomposed (DDC 3). With regard to nutritional status, 9/31 (29\%) showed good, 6/31 (19.3\%) moderate, and 16/31 $(51.6 \%)$ poor body condition.

The animals were found stranded over a 13-year period (from October 2008 to April 2020 ) along the Italian coastline $[13 / 31(41.9 \%)$ in Liguria, $7 / 31(22.6 \%)$ in Calabria, $5 / 31$ (16.1\%) in Campania, 3/31 (9.7\%) in Apulia, and 3/31 (9.7\%) in Sicily]. A map indicating stranding date and location is shown in Figure 1.

Supplementary Materials Table S2 presents the results of molecular, immunohistochemical, microbiological, and serological analysis, along with the type of infection (systemic or localized) based on whether organs other than the CNS tested positive by molecular testing for DMV [32]. The animals found stranded between 2008 and 2015 were diagnosed with the Mediterranean DMV variant, whereas those found between 2016 and 2020 were diagnosed with the DMV NE-Atlantic variant. Except for ID 2, in which the brain was the only organ that tested positive for DMV, all the other animals presented systemic DMV infection of at least two other organs besides the CNS and tested positive for the virus [32] (data not shown).

With regard to common neuropathogens in cetaceans (Sierra et al. 2020), 10/31 animals (32\%) presented with cerebral co-infection: T. gondii (7/10) (ID 1, 5, 16, 24, 26, 29, 30), T. gondii and Brucella ceti (1/10) (ID 14), ${ }^{\gamma} \mathrm{HV}(1 / 10)$ (ID 11) and T. gondii and $\gamma^{\gamma} \mathrm{HV}(1 / 10)$ (ID 20). Overall, immunostaining for $T$. gondii abs was positive in $6 / 9$ animals. In addition, microbiological analysis revealed P. damselae subsp. damselae in 5 animals (ID 11, 14, 21, 30, 31), Salmonella 1,4,[5], 12:i: in ID 16, L. ivanovii in ID 10, and L. innocua in ID 21.

Overall, immunostaining against CDV abs was positive in 24/31 animals. Noteworthy with regard to the strains circulating in the Mediterranean, 3 of the animals were from the 
group of $6(50 \%)$ that tested positive on molecular testing for the DMV Mediterranean variant, while 21 were from the group of 25 animals (80\%) that tested positive for the DMV NE-Atlantic variant. Anti-Morbillivirus, anti-T. gondii, and anti-Brucella spp. abs were detected in 13 animals. Anti-morbillivirus antibodies were detected in the serum of ID 6 (1:40), ID 11 (1:40), ID 14 (1:8), ID 17 (>1:256) and in the aqueous humour of ID 28 (1:128). Anti-T. gondii abs were detected in ID 1 (1:80 serum), ID 3 (>1:160 serum), ID 6 (1:80 serum), ID 11 (>1:40 serum), ID 14 ( $>1: 40$ serum, CSF, aqueous humour), ID 15 (>1:40 serum), ID 16 (>1:640 serum and aqueous humour), and ID 30 (>1:40 serum and aqueous humour). No evidence of anti-Brucella spp. abs was found in sera, CSF or aqueous humour in the samples from either of the dolphins tested. No results were obtained from ID 21 because of haemolysis.

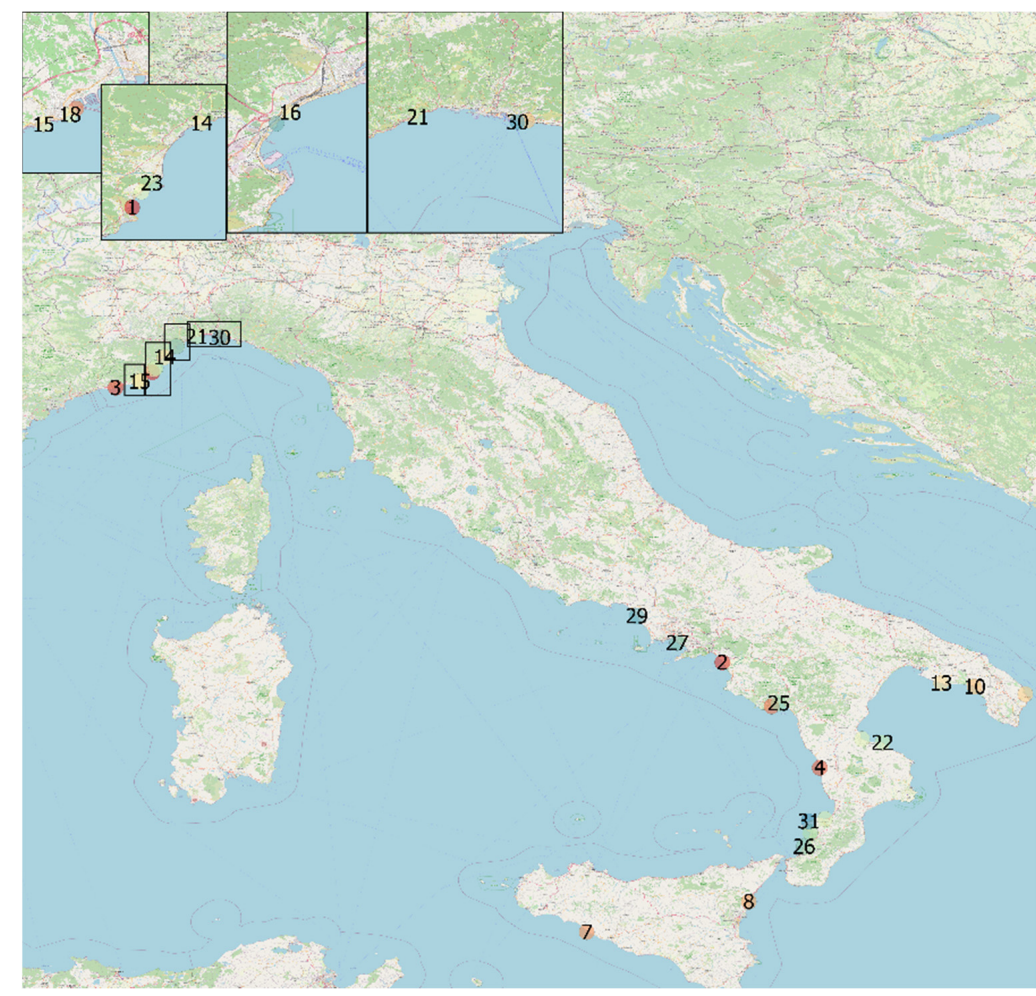

Figure 1. Stranding sites of cetaceans infected by dolphin morbillivirus, Italy, 2018-2020. Geographical mapping was created by M.I.C. with QGIS 3 software (QGIS Geographic Information System, QGIS association. www.QGIS.org, accessed on 29 January 2022) using the geographical coordinates found from the strandings.

Table 2 presents a description of CNS DMV-associated lesions and includes inflammatory lesions due to non-suppurative meningoencephalitis, which were classified as subacute or chronic, and acute lesions due to encephalopathy/encephalitis, comprising mainly neurodegenerative and reactive changes with minimal or absent inflammatory components [20,31,32]. In detail, the chronic form was described in only 1 animal (ID 17). Subacute forms were assigned to 17 animals (ID 1, 2, 6, 12, 14, 16, 18-24, 26, 28, 29, 31) presenting meningitis (Figure 2A) and mild to moderate perivascular cuffing (Figure 2A,B) consisting of lymphocytes and plasma cells. Acute forms were found in 13 animals (ID 3-5, $7-11,13,15,25,27,30$ ). Minimal to severe astro-microgliosis (Figure 2B,C,E) was present in 24 animals, frequently in those presenting inflammatory forms. Mild to moderate malacia (Figure 2D) was detected in 14 animals presenting inflammatory patterns (severe malacia was observed in 2 animals with acute forms [ID 7 and 8]). Minimal to severe neuronal necrosis (Figure 2B,E) was observed in 23 animals. Mild to severe spongiosis in white matter was a common feature in 27 animals. Three showed severe myelinopathy (ID 9, 10, 28) (Figure 3) and were selected for characterization by double IF and IHC. INCBs 
were detected in only one animal (ID 19) (Figure 2G), which presented severe subacute meningoencephalitis. Finally, haemorrhage was present in 16 animals.

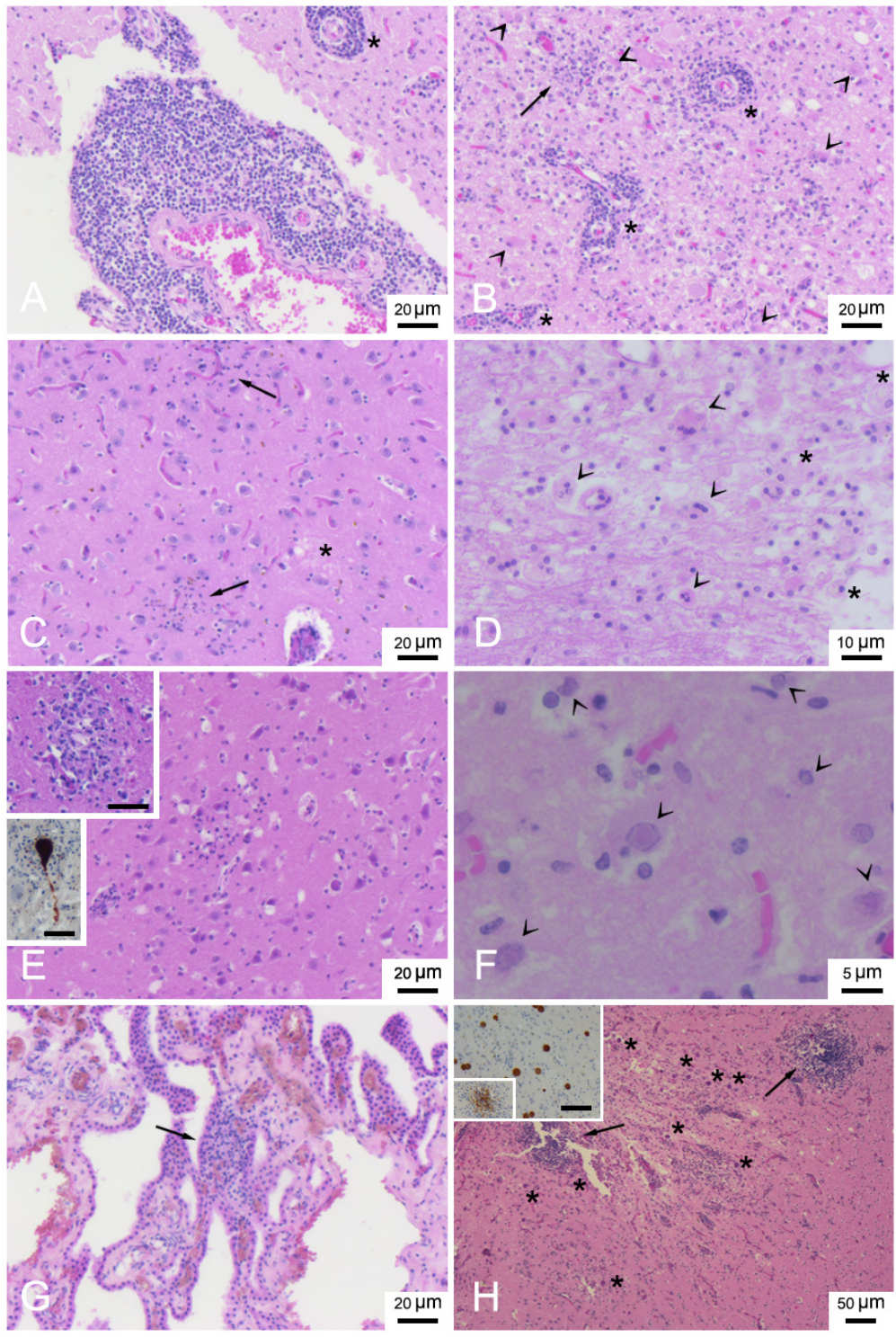

Figure 2. Neuropathologic lesions in stranded cetaceans with DMV infection. (A) Frontal cortex (ID 19). Severe non-suppurative meningitis and perivascular cuffing (asterisk). HE. (B) Frontal cortex (ID 19). Severe encephalitis with non-suppurative perivascular cuffing (asterisks), neuronophagic nodule of microglia cells (arrow) and diffuse astro-microgliosis with gemistiocytes (arrowheads). HE. (C) Frontal cortex (ID 16). Microgliosis (arrows) and oedema (asterisk), HE. (D) Cerebellum (ID 7). Malacic area with gitter cells (asterisks) and syncytia cells (arrowheads), HE. (E) Parietal cortex (ID 31). Diffuse acute neuronal necrosis (eosinophilic and shrunken neurons) and microgliosis. Upper inset: occipital cortex (ID 24). Neuronophagic nodule of microglia cells. Scale bar $=20 \mu \mathrm{m}$. HE. Lower inset: pons (ID 16). Positive labelling of a neuron inside a neuronophagic nodule. Scale bar $=25 \mu \mathrm{m}$. IHC for DMV. (F) Occipital cortex (ID 19). Eosinophilic intranuclear inclusion bodies (arrowheads). HE. (G) Plexus choroideus (ID 14). Focal and minimal non-suppurative plexus choroiditis (arrow). HE. (H) Frontal cortex (ID 16). Severe necrotizing granulomatous encephalitis with protozoan cysts (asterisks) and two nodules of microglia and mononuclear inflammatory cells (arrow). HE. Inset: Frontal cortex (ID 16). Positive labelling of a nodule of microglia and mononuclear inflammatory cells and several protozoan cysts. Scale bar $=50 \mu \mathrm{m}$. IHC for Toxoplasma gondii. 
Table 2. DMV-associated lesions in CNS, stage of infection, and co-infection in tissue samples from 31 animals.

\begin{tabular}{|c|c|c|c|c|c|c|c|c|c|c|c|c|c|}
\hline \multirow{2}{*}{$\begin{array}{l}\text { Case } \\
\text { No. }\end{array}$} & \multicolumn{8}{|c|}{ Cerebral and Cerebellar Cortex } & \multirow{2}{*}{ Lesions in Other Regions } & \multirow{2}{*}{ Associated Lesions } & \multirow{2}{*}{ SI } & \multirow{2}{*}{ Co-Infections } & \multirow{2}{*}{ References } \\
\hline & $\mathbf{M}$ & PC & Astro-Mg & Malacia & NN & $\mathrm{S}$ & INCIBs & $\mathbf{H}$ & & & & & \\
\hline 1 & ++ & ++ & + & - & +++ & + & - & + & $\begin{array}{c}\text { Diffuse and mild NS } \\
\text { meningoencephalitis associated with } \\
\text { focal and minimal NS plexus } \\
\text { choroiditis }\end{array}$ & $\begin{array}{l}\text { Protozoan tissue cysts and } \\
\text { syncytia }\end{array}$ & $\mathrm{S}$ & T. gondii & {$[1,9,10,30,37]$} \\
\hline 2 & +++ & +++ & +++ & + & +++ & ++ & - & + & - & Syncytia & $\mathrm{S}$ & - & {$[1,10]$} \\
\hline 3 & - & + & - & - & - & +++ & - & - & Mild NS myelitis & - & $\mathrm{A}$ & - & {$[1,37]$} \\
\hline 4 & - & - & - & - & ++ & +++ & - & + & $\begin{array}{c}\text { Multifocal and mild NS plexus } \\
\text { choroiditis }\end{array}$ & & A & - & [1] \\
\hline 5 & - & + & - & - & - & ++ & - & - & - & - & $\mathrm{A}$ & T. gondii & [1] \\
\hline 6 & + & ++ & ++++ & - & +++ & ++ & - & + & $\begin{array}{l}\text { Diffuse and mild NS } \\
\text { meningoencephalitis }\end{array}$ & - & $\mathrm{S}$ & - & [10] \\
\hline 7 & - & - & +++ & ++++ & ++ & +++ & - & + & - & Syncytia & $\mathrm{A}$ & - & \\
\hline 8 & - & - & +++ & ++++ & ++ & +++ & - & - & Perivasal oedema & Syncytia & $\mathrm{A}$ & - & \\
\hline 9 & + & - & + & - & ++ & ++++ & - & - & - & - & $\mathrm{A}$ & - & \\
\hline 10 & - & - & ++ & ++ & ++++ & ++++ & - & + & - & Purkinje cell loss & $\mathrm{A}$ & L. ivanovii & {$[10,12]$} \\
\hline 11 & - & - & ++ & - & - & ++ & - & - & Mild NS plexus choroiditis & - & $\mathrm{A}$ & $\begin{array}{c}\gamma \mathrm{HV} \text { and } \\
\text { Photobacterium } \\
\text { damselae subsp. } \\
\text { damselae } \\
\end{array}$ & {$[10,12]$} \\
\hline 12 & + & ++ & ++ & ++ & ++++ & +++ & - & + & - & $\begin{array}{c}\text { Suppurative encephalitis } \\
\text { characterized by degenerate } \\
\text { neutrophils }\end{array}$ & $\mathrm{S}$ & - & {$[10,12]$} \\
\hline 13 & - & - & - & ++ & + & +++ & - & + & - & - & $\mathrm{A}$ & - & {$[10,12]$} \\
\hline 14 & +++ & +++ & +++ & ++ & ++ & + & - & + & $\begin{array}{c}\text { Diffuse and moderate NS } \\
\text { meningoencephalitis associated with } \\
\text { focal and minimal NS plexus } \\
\text { choroiditis }\end{array}$ & $\begin{array}{l}\text { Protozoan tissue cysts and } \\
\text { syncytia Granulomatous } \\
\text { encephalitis }\end{array}$ & $S$ & $\begin{array}{l}\text { Brucella ceti, T. gondii } \\
\text { and Photobacterium } \\
\text { damselae subsp. } \\
\text { damselae }\end{array}$ & {$[28,29]$} \\
\hline 15 & - & - & + & + & - & ++ & - & - & - & - & $\mathrm{A}$ & - & [10] \\
\hline 16 & ++ & +++ & +++ & ++ & ++ & ++ & - & + & $\begin{array}{l}\text { Diffuse and moderate NS } \\
\text { meningoencephalitis and oedema }\end{array}$ & $\begin{array}{l}\text { Protozoan tissue cysts and } \\
\text { syncytia Granulomatous } \\
\text { necrotizing encephalitis }\end{array}$ & $S$ & $\begin{array}{l}\text { T. gondii and } \\
\text { Salmonella } \\
\text { 1,4,[5],12:i:-; }\end{array}$ & {$[10,27]$} \\
\hline 17 & +++ & ++ & - & - & - & ++ & - & + & $\begin{array}{c}\text { Diffuse and moderate NS } \\
\text { meningoencephalitis and myelitis }\end{array}$ & - & $\mathrm{C}$ & - & \\
\hline 18 & ++ & - & + & - & ++ & +++ & - & + & - & - & $\mathrm{S}$ & - & \\
\hline
\end{tabular}


Table 2. Cont.

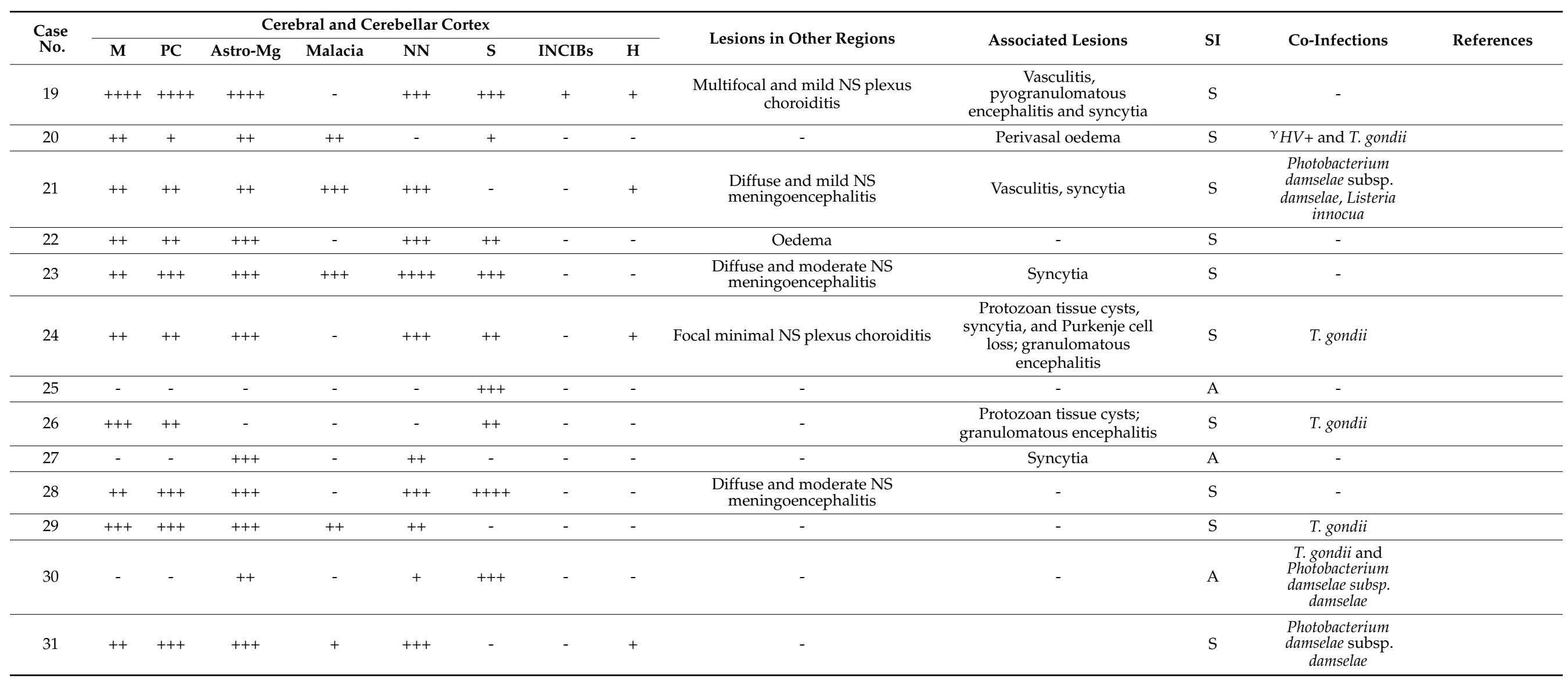

Legend: DMV, dolphin morbillivirus; CNS, central nervous system; NS, non suppurative; M, meningitis; PC, perivascular cuffing; Mg, microgliosis; INCIBs, intranuclear and/or intracytoplasmatic inclusion bodies; NN, neuronal necrosis; H, haemorrhage; S, spongiosis. Absent (-); minimal (+); mild (++); moderate (+++); severe (++++); SI, stage of infection; A, acute; $\mathrm{S}$, subacute; $\mathrm{C}$, chronic. 


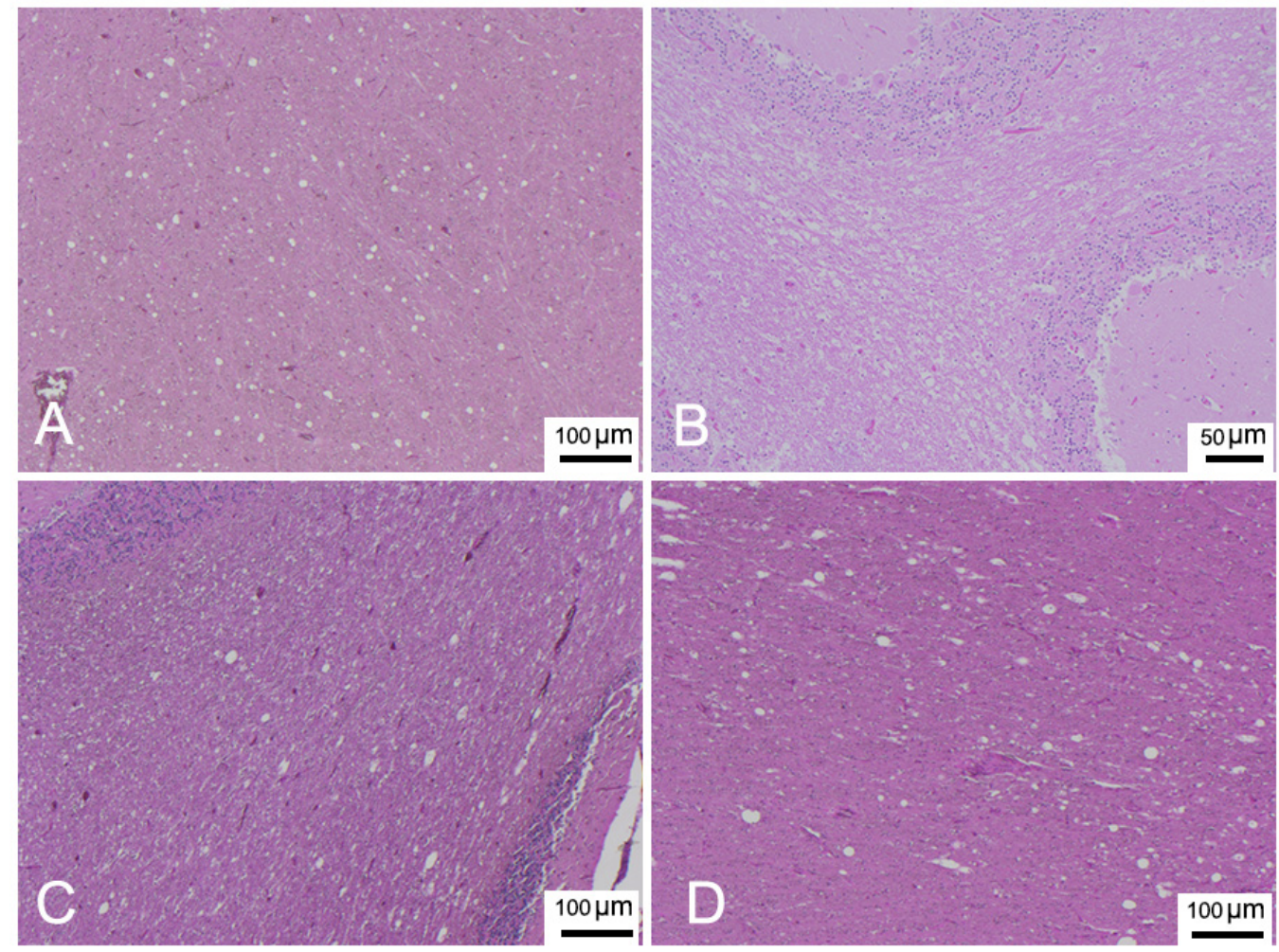

Figure 3. (A) Parietal cortex (ID 9). Spongiosis in white matter. HE. (B) Cerebellar cortex (ID 10). Severe myelinopathy, HE. (C) Occipital cortex (ID 28). Spongiosis in white matter. HE. (D) Cerebellar cortex (ID 28). Spongiosis in white matter. HE.

Lesions in other anatomical regions included: diffuse non-suppurative meningoencephalitis in all sections examined, along with the cerebellar and the cerebral cortex, in 8 animals (ID 1, 6, 14, 16, 17, 21, 23, 28), non-suppurative plexus choroiditis (Figure 2G) in 6 animals (ID 1, 4, 11, 14, 19, 24), non-suppurative myelitis in 2 animals (ID 3 and 17), oedema (Figure 2C) in 3 animals (ID 8, 16, 22). Associated lesions comprised syncytia (Figure 2D) in 11 animals (ID 1, 2, 7, 8, 14, 16, 19, 21, 23, 24, 27), protozoan tissue cysts associated with granulomatous encephalitis (Figure 2H) in 4 animals (ID 14, 16, 24, 26), protozoan tissue cysts alone in 1 animal (ID 1), Purkinje cell loss in 2 animals (ID 10 and 24), vasculitis in 2 animals (ID 19 and 21), suppurative and pyogranulomatous encephalitis in 1 animal each (ID 12 and 19, respectively). Three animals (ID 5, 20, 29) presented no protozoan cysts, although molecular analysis indicated co-infection with the parasite.

No differences in histopathological features and in stage of infection were found between the two strains (unfortunately, no cases from the 2013 unusual mortality event (UME) were included in the present study). No statistically significant difference between the two strains for any of the parameters was shown by either univariate or multivariate analysis.

IF labelling with anti-myelin ab in areas characterized by myelin damage in 3 animals (ID 9, 10, 28) revealed myelinopathy, with a marked reduction in myelin density and a partial loss of tissue organization (Figure 4B,C) compared to the negative control (Figure 4A), and large areas completely devoid of myelin (Figure 4E). In addition, double staining with CDV indicated viral infection in the demyelinated areas, more pronounced in ID 10 and less so in ID 28 (Figure 4D,F, respectively). 


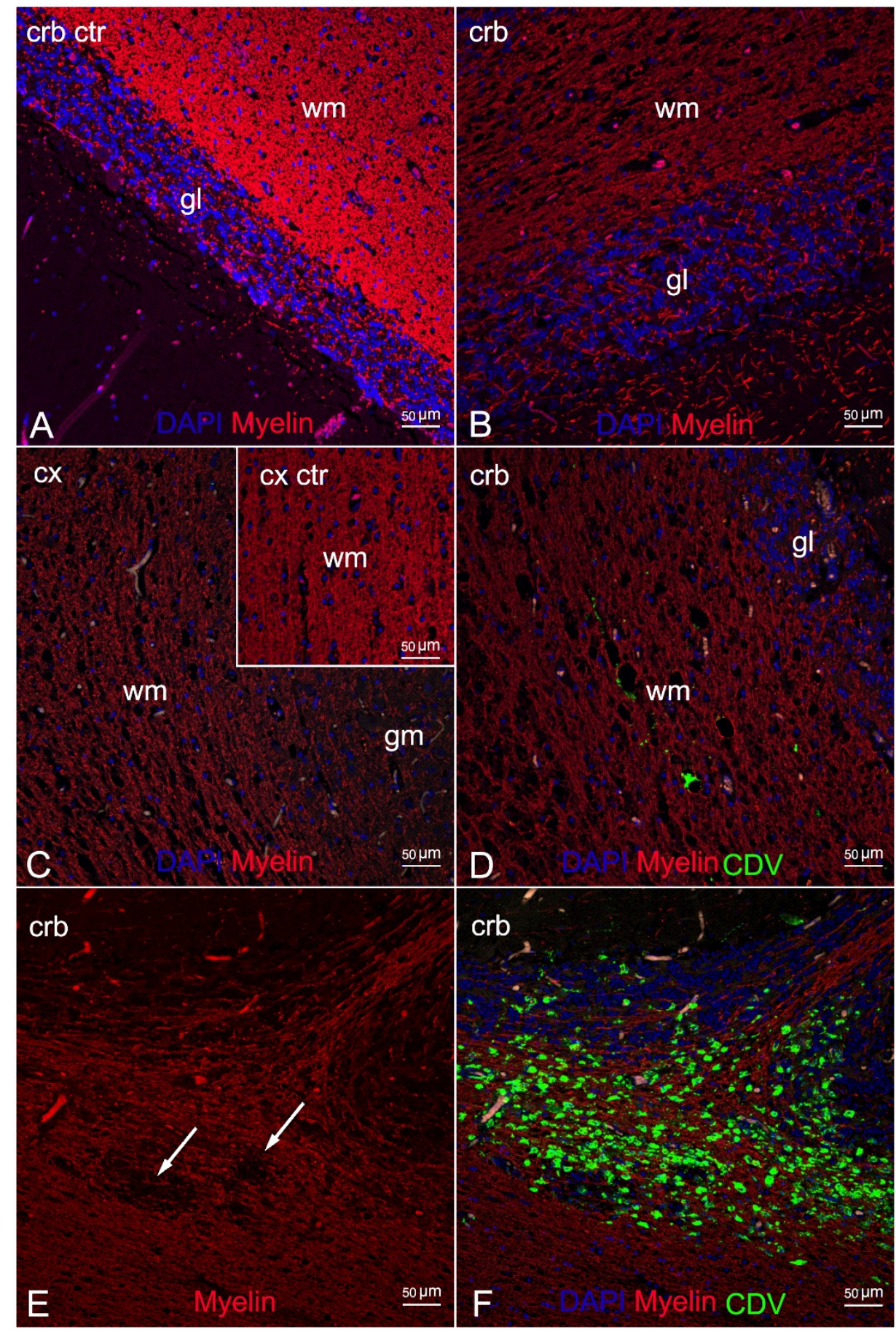

Figure 4. Morphological characterization of myelinopathy by means of double IF for myelin and DMV. (A) Cerebellar cortex (negative control). Myelinated white matter. (B) Cerebellar cortex (ID 28). Marked reduction in the myelin density with partial loss of tissue organization. (C) Cerebral cortex (ID 9). Severe reduction of myelin density, 20x. Inset: cortical cortex (negative control). Myelinated white matter. (D) Cerebellar cortex (ID 28). Limited DMV infection of the demyelinated white matter. (E) Cerebellar cortex (ID 10). Demyelinated white matter with complete loss of myelin (arrows). (F) Cerebellar cortex (ID 10). Severe DMV infection of the demyelinated white matter and the granular layer. Legend: wm, white matter; gm, grey matter; gl, granular layer; Cx, cortex; Crb, cerebellum; $\mathrm{Ctr}$, negative control; DAPI, 4,6-diamidino-2-phenylindole; CDV, canine distemper virus.

Comparison of double staining between the anti-GFAP and the anti-CDV abs showed marked astrocytosis, with reactive astrocytes inside and around the demyelinated areas 
(Figure 5B,C) but very little viral colonization in these cells, with a single area of overlapping in ID 10 (Figure 5D).

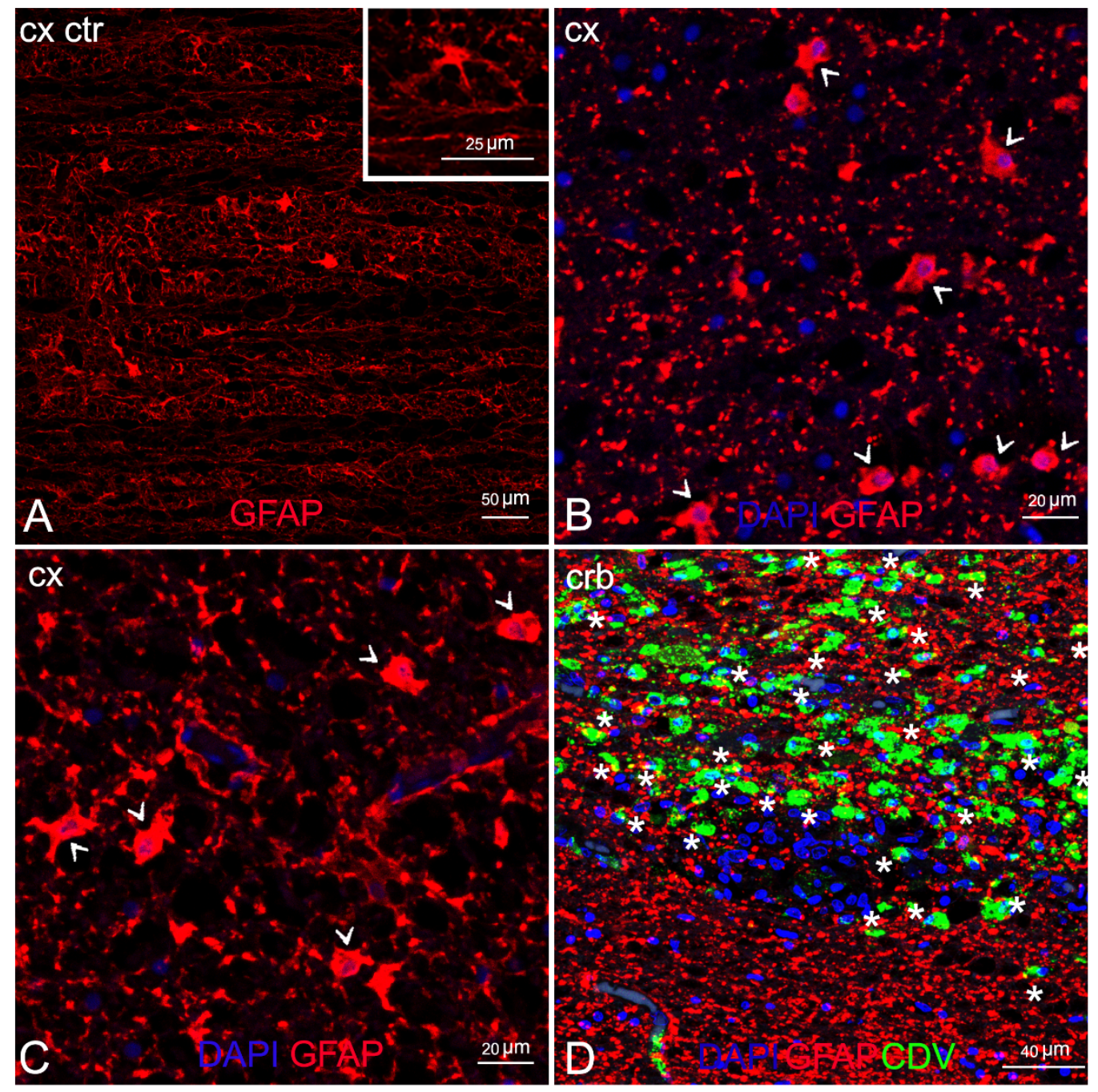

Figure 5. Characterization of demyelinated areas by means of double IF for astrocytes and DMV. (A) Cerebral cortex (negative control). Inset: cerebral cortex (negative control). Astrocyte in restingstate. (B) Cerebral cortex (ID 9). Several reactive astrocytes (arrowhead). (C) Cerebral cortex (ID 28), Several reactive astrocytes (arrowhead). (D) Cerebellar cortex (ID 10). Viral infection in astrocytes, co-localization anti-CDV and anti-GFAP visible in yellow (asterisks). Legend: Cx, cortex; Crb, cerebellum; Ctr, negative control; DAPI, 4,6-diamidino-2-phenylindole; CDV, canine distemper virus.

Double IF labelling with anti-CDV, anti-Iba1, and anti-NeuN demonstrated the neuronal and microglial origin of the morbillivirus antigen-bearing cells (Figures 6 and 7). In addition, severe and diffuse microglia activation was observed in all tissue sections (Figure 6B). No oligodendrocyte origin of DMV infection could be found by either double IF or through double IHC, since both anti-Olig2 markers employed failed in staining the oligodendroglia cells. 


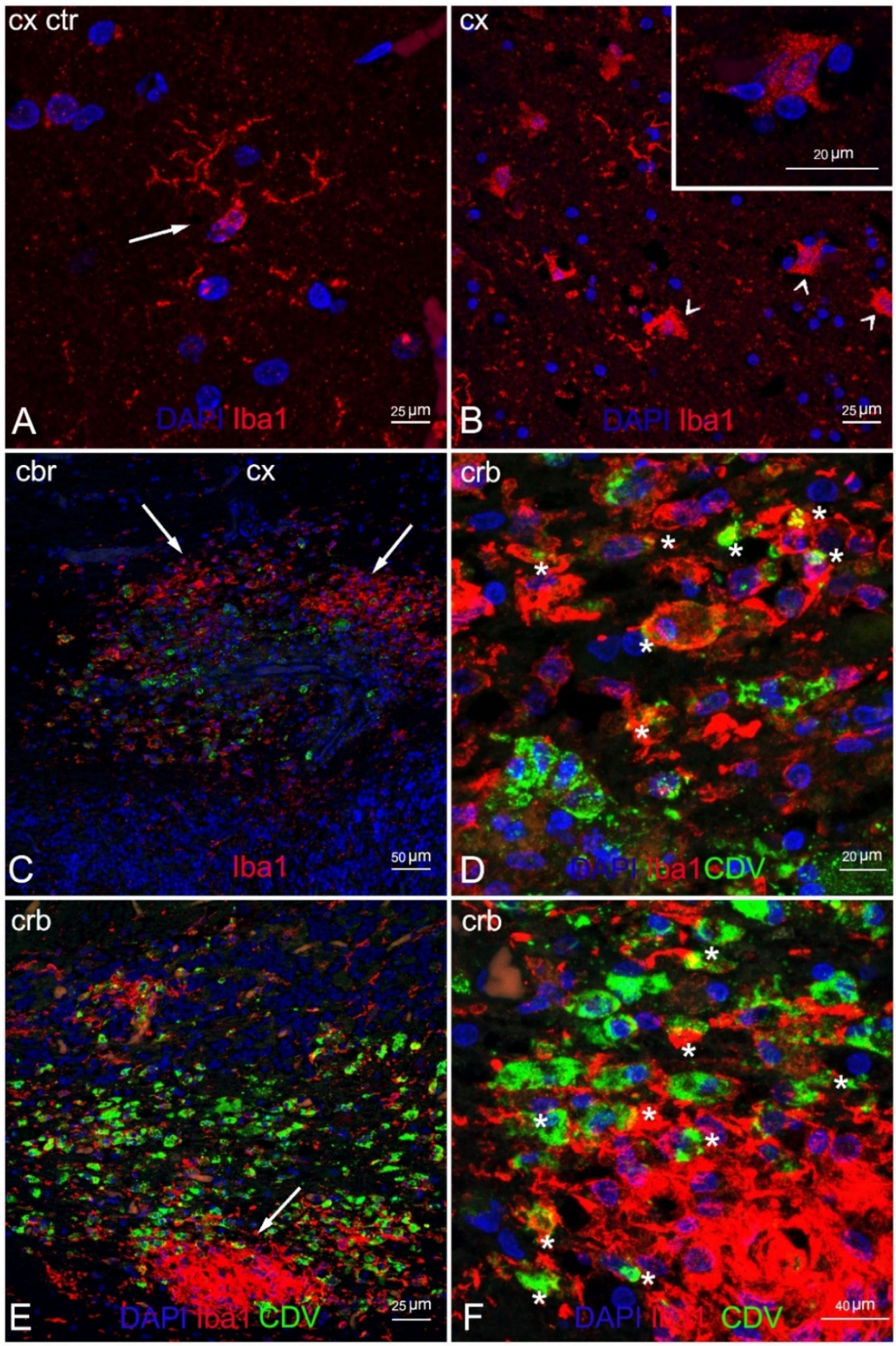

Figure 6. Characterization of demyelinated areas by means of double IF for microglia and DMV. (A) Cerebral cortex (negative control). Microglia in normal condition (resting state) (arrow). Note the typical ramified morphology characterizing these cells in healthy tissues. (B) Cerebral cortex (ID 28). Reactive microglia in demyelinated white matter (arrowhead). Inset: magnification of reactive microglia. (C) Cerebellar cortex (ID 10). Microgliosis in white matter (arrow) infected with DMV. (D) Magnification of image 4C. Marked co-localization of microglia and DMV (asterisks). (E) Cerebellar cortex (ID 10). Microglial nodule (arrow) positive for DMV. (F) Magnification of image 6E. Co-localization of microglia and DMV (asterisks) in the periphery of the nodule. Legend: $\mathrm{Cx}$, cortex; Crb, cerebellum; Ctr, negative control; DAPI, 4,6-diamidino-2-phenylindole; CDV, canine distemper virus. 

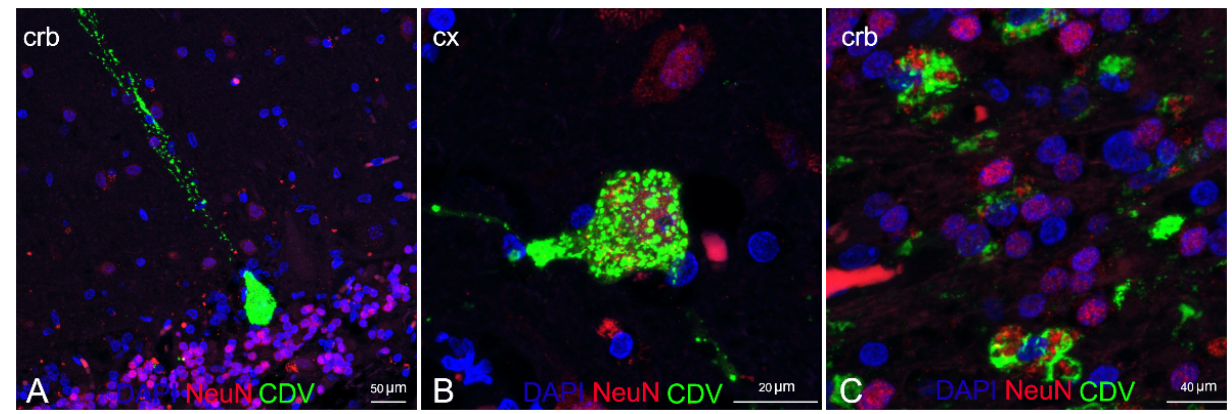

Figure 7. Characterization of DMV CNS infection by means of double IF for neurons and DMV. (A) Cerebellar cortex (ID 28) Purkenje cell positive for positive for DMV. (B) Cerebral cortex (ID 28). Cortical neuron positive for DMV. (C) Cerebellar cortex (ID 10). Neurons of granular layer positive for DMV. Legend: Cx, cortex; Crb, cerebellum; DAPI, 4,6-diamidino-2-phenylindole; CDV, canine distemper virus.

\section{Discussion}

CeMV has been responsible for several outbreaks and inter-epidemic lethal diseases worldwide. Three unusual mortality events (UMEs) associated with DMV infection in the Mediterranean basin were reported for Italy and Spain $(2011,2013,2016)[12,38,39]$, in addition to single disease descriptions of DMV infection along the Italian coastline reported by the C.Re.Di.Ma. in standard annual mortality rates [40-44].

Despite high levels of biomolecular positivity to DMV, the majority of the infected animals in the 2011 and 2013 Mediterranean UMEs presented milder lesions and pathological changes not directly referable to the virus but rather indicating chronic systemic DMV infection associated with secondary infection accompanied by scarce or absent immunoreactivity towards the virus [19,32,39]. In contrast, during the $2016 \mathrm{UME}$, pathological findings suggestive of acute/subacute disease were noted that resembled those reported during the Mediterranean outbreaks of 1990-1992 and 2006-2008 [45], with Morbillivirus immunostaining becoming a common feature in tissues testing positive on molecular tests [12].

Recent phylogenic and phylogeographic analysis [10] on 16 strains that circulated in the last 30 years in the Mediterranean confirmed a general well-conserved homology among the strains, with an overall sequence identity $>98 \%$. A novel lineage of Atlantic origin, named NE-Atlantic strain because first detected in animals found stranded along the coasts of Galicia and Portugal in 2011-2013, started to replace the Mediterranean strain by late 2015 in Italian waters [10-12]. The first description of the NE-Atlantic strain in the Mediterranean basin refers to a sperm whale (Physeter macrocephalus Linnaeus, 1758) found stranded on the coast of Vasto (CH) in 2014 [10] during a mass stranding episode that involved seven individuals [46]. The animal may have been responsible for the transmission of the new strain in Italian waters, given the role of spillover host of this species [47] and the date of stranding recorded almost 2 years before the first description in small odontocetes inhabiting the same geographical area.

For this study, we retrieved the neuropathological reports on brain tissue samples from 188 cetaceans submitted to the C.Re.Di.Ma. for 2007-2020. Between 2007 and 2015, during which the DMV Mediterranean strain began circulating, 13\% (9/69) of the tissue samples tested positive on molecular testing. Differently, between 2016 and 2020, when only the NE-Atlantic strain was known to circulate in Italian waters, 23\% (28/119) of the brain samples tested positive for the virus. With reference to antigen detection by IHC analysis, 50\% (3/6) of the tissue samples obtained during the first reporting period (DMV Mediterranean strain) showed positive labelling, whereas the percentage of brains with positive immunolabelling was increased by $80 \%(21 / 25)$ for the second reporting period (DMV NE-Atlantic strain). Our data, albeit not statistically significant because of the small number of specimens infected with the DMV Mediterranean strain that precluded analysis, suggest a higher neurotropic potential of the NE-Atlantic strain compared to the 
Mediterranean strain. The new variant, because of its higher virulence for the CNS, does not allow the affected animals to survive the acute/subacute stage of infection, different from observations recorded during the UMEs of 2011 [19] and 2013 [39] in which the chronic forms predominated.

Almost half (45.2\%) of the animals infected with the new variant were adults. This could mean that the virus was circulating within an immunologically naïve population (unfortunately, the serological analysis did not discriminate between the two variants), and resulted in severe disease. This observation differs from the events reported during the two UMEs which, probably due to a lack of specific antiviral immunity, involved mainly new-born, juveniles, and subadults [38,39].

Further studies would be of paramount importance to confirm our hypothesis for a higher neurotropic potential of the NE-Atlantic strain, with a focus on other target organs (e.g., lungs, spleen, lymph nodes) to better characterize systemic disease severity.

The present study describes the neuropathological findings in cetaceans found stranded along the Italian coastline and which received a morphological diagnosis of CNS inflammation or showed neurodegenerative and reactive changes referable to morbillivirus infection, as confirmed by molecular testing. The neuropathological changes due to DMV infection we noted are shared by previous reports $[1,2,18,20,32]$ and are consistent with an earlier stage of acute and subacute disease: neurodegenerative and reactive alterations accompanied or not by mild-to-severe inflammatory lesions. In many animals (74\%) there was minimal-to-severe diffuse neuronal necrosis in both the acute and the subacute/chronic forms, with shrunken eosinophilic neurons and neuronophagic nodules, respectively. This high percentage differs from a recent report by Sierra and colleagues [2] and may be attributable to the stage of infection (chronic forms) described in animals from the Canary Islands. Malacia was commonly observed in acute presentations characterized by gitter cells in almost half of the animals (45\%). Syncytia, present in one-third of the animals in our sample, may be considered a characteristic feature of DMV since it was found in brains not co-infected with neurotropic agents (except for ID 1, 14, 16), as reported by Sierra and colleagues [2]. Half of the animals showed haemorrhage, a non-specific lesion observed also in cases of co-infection.

The most common CNS changes were astro-microgliosis and spongiosis of the white matter: astro-microgliosis was noted in 77\% of animals, often in moderate and severe form, while spongiosis was seen in nearly all animals (87\%) except for four (ID 21, 27, 29, 31). Minimal-to-severe non-suppurative inflammatory infiltrate in the meninges and around the vessels was responsible for a gradual transition to later stages of the disease. It was observed in almost $68 \%$ of animals (ID 5 and 9 presented acute infections). Only one animal (ID 19) presented a few neurons and astrocytes with eosinophilic intranuclear inclusion bodies, a typical and rather rare finding in DMV brain infection [2,20]. No co-infection with herpesvirus was reported in this animal. Purkinje cell loss was observed in $6 \%$ of the animals; this alteration is considered reliable only in very fresh and fresh cerebellum tissues (DDC 1 and 2). In line with previous data [2,20], vasculitis was seldom present (6\%) and not associated with co-infection with common cetacean pathogens in our study. Mildto-moderate non-suppurative plexus choroiditis was noted in six animals (19\%), four of which with co-infection with other neurotropic agents. Of note is that this neuroanatomical region is the initial site of DMV brain invasion by the hematogenous route [48].

The spinal cord was rarely included in the sampling set during necropsy. Spinal cord lesions (non-suppurative myelitis) were observed in only two animals. In addition, diffuse non-suppurative meningoencephalitis was diagnosed in eight animals for which the whole cerebrum was available (exam not limited to only the cerebral and cerebellar cortex). These data highlight the importance of exhaustive sampling during post mortem examination.

In line with a previous description [20], immunostaining for the virus was not consistent for all tissue samples: positive labelling was achieved in $77 \%$ of cases $(24 / 31)$.

We detected cerebral co-infection by common cetacean neurotropic agents [2] in one-third of the animals $(10 / 31,32 \%)$. The most frequent was T. gondii $(9 / 10)$, alone 
$(7 / 10)$ or associated with Brucella ceti or ${ }^{\gamma}$ Herpesvirus (HV) in the other two animals. Moreover, ${ }^{\gamma} \mathrm{HV}$ was also detected in one supplementary case. The activity of these agents in the pathogenesis of lesions cannot be ruled out, since histopathological alterations in co-infection can be a consequence of the overlapping of two or more pathogens [2].

T. gondii is a zoonotic coccidian protozoan regarded as a primary pathogen for cetaceans and responsible for toxoplasmosis, a major emerging disease in these species [25,49]. Five out of nine infected animals (ID 1, 14, 16, 24, 26) showed tissues cysts, often associated with moderate-to-severe granulomatous encephalitis, as reported in terrestrial and marine species [2,50]. Tissue cysts and zoites were confirmed by IHC labelling. Three animals tested positive on molecular testing but no cysts could be found in the sections we examined.

Brucellosis is a widespread zoonosis of public health and economic concern in many areas of the world [28]. Meningoencephalomyelitis is one of the most common lesions caused by B. ceti in cetaceans, [2], although infections often show subclinical development in these species [51]. The only animal (ID 14) co-infected with B. ceti (and T. gondii) showed moderate non-suppurative meningitis and focal and minimal plexus choroiditis. Although both lesions are regarded as characteristic for this bacteria [2,28], these features have also been described in animals presenting with DMV infection alone and characterized by a more severe pattern (ID 19).

Herpesvirus infection carries neuropathological significance in cetaceans. CNS damage has been confirmed in association with $\alpha \mathrm{HV}$ [52-54], and lesions typically referable to the infection are consistent with non-suppurative meningoencephalitis. Identifying the pathogenic role of ${ }^{\gamma} \mathrm{HV}$ is more difficult, since the association between encephalitis and meningoencephalitis and ${ }^{\gamma} \mathrm{HV}$ infection was first established in 2021 [55] in 8 animals and in one more with co-infection with $\alpha \mathrm{HV}$. Since the pathological changes observed in 2 animals with ${ }^{\gamma} \mathrm{HV}$ co-infection (ID 11 and 20) closely matched the lesions characteristic for $\mathrm{DMV}$, a specific role for ${ }^{\gamma} \mathrm{HV}$ in the neuropathogenesis of these lesions cannot be confirmed or ruled out.

Noteworthy with regard to cerebral co-infection with bacterial agents other than Brucella spp. is the isolation of Photobacterium damseale subs. damselae in five animals, of Salmonella 1,4,[5],12:i:-, L. ivanovii, and L. innocua in 1 animal each. P. damselae subsp. damselae is increasingly found in stranded marine mammals but little is known about its precise etiological responsibility $[39,56]$.

As concerns the pathological significance of Salmonella 1,4,[5],12:i:- in cetaceans, very few cases have been documented to date, one of which is ID 16 [27]. The detection of Salmonella 1,4,[5],12:i:- in the brain and other tissues and biological fluids, including the blood, was attributed to a septicemic form of infection, with evidence of microscopic intestinal and vascular lesions (intestinal necrosis, vascular embolus in intestinal mesentery) [27].

Listeria ivanovii, widely distributed in nature, is a potential cause of listeriosis in ruminants and in immunocompromised humans, which is why it is recognized as a pathogenic agent along with Listeria monocytogenes [57], although a neuropathological role has not yet been confirmed [57,58]. The lesions observed in the brain of ID 10 were clearly suggestive of viral infection; a role of the bacteria in the neuropathogenesis of these features was ruled out for this reason.

L. innocua is generally considered nonpathogenic. Although two cases of Listeria innocua meningoencephalitis were described in domestic animals, one in a ewe (Ovis aries Linnaeus, 1758) [59] and the other in a bull (Bos taurus Linnaeus, 1758) in northwest Italy [60], no descriptions in marine mammals have been reported to date. Histopathological findings observed in the fatal case involving the bull [60], related to severe vasculitis often associated with large areas of necrosis and haemorrhages, may not exclude a potential role of L. innocua in exacerbating the lesions found in ID 21.

Serological analysis in $41 \%$ of the animals succeeded in detecting morbillivirus infection in $38 \%$ (ID 6, 11, 14, 17, 28). The negative serological findings of DMV-positive cases (ID 1, 3, 15, 16, 30) by PCR, given the simultaneous detection of other abs (anti-T. gondii), supports the false-negative results, which are reported to occur in serological tests 
performed with heterologous Morbillivirus strains [32]. The absence of abs in $23 \%$ of the animals (ID 4, 18, 23) could indicate a possible immunocompromised host response or false-negative results, as reported before.

There is abundant literature on demyelinating lesions in morbillivirus infection in pinnipeds and dogs [13-16], probably in relation to the well-documented high phylogenetic correlation between CDV and phocine distemper virus [16]; however, few descriptions of myelin changes have been reported in cetaceans with CeMV infection so far [12,17-19]. In some cases confirmed by Luxol Fast Blue staining, the procedure has not always proven effective in showing demyelination [20].

Here we provide a comprehensive description of neuropathological changes in the cerebral and the cerebellar cortex of three animals characterized by severe spongiosis by means of double IF staining with specific biomarkers targeting the myelin and the brain cell populations (neurons and glial cells) coupled with the anti-CDV ab. The analysis with anti-myelin marker detected severe myelinopathy, with a reduction in myelin density and large areas completely devoid of myelin, confirming demyelination in the animals. In addition, the anti-CDV marker revealed this alteration in the presence and the absence of direct morbillivirus infection in these brain areas. A plausible explanation for the difference is the different stages of infection since demyelination is associated with viral replication in earlier stages of infection [13].

Double IF analysis using anti-GFAP, anti-NeuN, anti-Iba1 abs and coupled with antiCDV ab showed cellular activation and viral localization of the brain cell populations inside and around the areas affected by myelinopathy. These findings provide new information about the pathogenesis of the infection.

Unlike previous descriptions of demyelinated areas in CDV infection [13], and despite marked astrocytes activation, we found very few astroglial cells infected with the virus. This observation is shared by an ultrastructural description by means of double IF analysis carried out in cetaceans affected by brain only forms of infection (BOFDI) [61]. We noted marked microglial activation, which was evident in all animals with severe viral infection of the cells. This feature is very common in canine brains with CDV infection, in which oligodendrocyte/myelin damage results from virus-induced microglia activation, which releases myelinotoxic reactive oxygen species $[13,14,62]$.

Dual analysis with anti-NeuN and anti-CDV abs confirmed the neuronal origin of the antigen-bearing cells, as largely documented in CeMV infections [1,20,30,32].

Unfortunately, we obtained no information on oligodendrocytes infection or on oligodendrocytes ultrastructural changes as both anti-Olig2 abs failed to target the oligoglial cells. Therefore, several questions regarding the pathogenesis of demyelination remain unanswered: is the white matter damage a result of microglial activation induced by the virus, which we successfully documented, or rather a consequence of direct viral infection of this cell population, evaluable by observation of co-localization, as previously reported in CDV infection [13,14,62].

Future studies should be carried out using different oligodendrocyte markers, such as 2'-3'-cyclic nucleotide-3'-phosphatase (CNP) or galactocerebroside (GC), associated with the CeMV marker in dual IF. Another future area of focus is the comparative evaluation of anatomical sections of the entire brain and cerebellum to characterize the variety of cell changes occurring during CeMV brain infection.

To the best of our knowledge, this is the first study to describe myelin damage and microglial changes, as evidenced by IF analysis in cetacean brains affected by CeMV infection. The study provides novel data on ultrastructural pathology and neuropathogenetic alteration in systemic CeMV infection. To date, only one study on BOFDI forms has been published [61]. Finally, this is the first study to use confocal laser-scanning microscopy for in-depth analysis of CeMV infection. 


\section{Conclusions}

A novel DMV strain, named NE-Atlantic strain, started to replace the DMV Mediterranean strain circulating in Italian waters by late 2015. Based on molecular and immunohistochemical data, this new strain seems to possess a higher neurotropic potential and to cause more severe acute/subacute disease than previously observed during the 2011 and 2013 UMEs. The most frequently observed DMV-associated lesions were astro-microgliosis, neuronal necrosis, spongiosis, malacia, and non-suppurative meningoencephalitis. Coinfection or secondary infection in one-third of the animals may have been a contributory factor to stranding. A myelin-specific biomarker proved effective in demonstrating myelin damage in cetaceans with DMV infection. Morbillivirus antigen-bearing cells of neuronal and microglia origin inside and around demyelinated areas were associated with marked astro and microglia reactivity. Very little morbillivirus staining was evident in astrocytes. These findings further our understanding of DMV-associated brain lesions, shed light on their pathogenesis, and underscore the importance of CNS examination during forensic analysis.

Supplementary Materials: The following are available online at https:/ /www.mdpi.com/article/10 .3390/ani12040452/s1, Figure S1: Western Blot to evaluate specific reactivity of different polyclonal anti- bodies against Stenella coeruleoalba; Table S1: Anamnestic and stranding data of thirty-one animals under study; Table S2: Results of molecular, immunohistochemical, microbiological and serological investigations and type of infection of thirty-one animals under study.

Author Contributions: Conceptualization, F.G., C.C., S.M. and G.D.G.; data curation, F.G. and C.G.; formal analysis, F.G., C.C., G.D.G., M.I.C. and C.G.; funding acquisition, C.C.; investigation, F.G., B.I, M.G., P.C., L.S., A.F., P.G., A.D., T.A., S.P., F.D.N., G.L., A.P., C.E.D.F. and R.P.; methodology F.G., C.G. and C.C.; software, M.I.C. and F.G.; supervision, M.C., G.D.G. and C.C.; writing-original draft, F.G., C.G., P.G. and P.C.; writing—review and editing, G.D.G., E.S. and C.G. All authors have read and agreed to the published version of the manuscript.

Funding: This research was funded by the Italian Ministry of Health (Ricerca Corrente 2018 IZS PLV 09/18).

Institutional Review Board Statement: Not applicable. Ethical review and approval were waived for this study, as neither animals were sacrificed nor experiments were performed with live animals. The permission for the management of dead stranded cetaceans was issued by the Italian Ministry of Health.

Data Availability Statement: The data presented in this study are available within the article and the Supplementary Materials.

Acknowledgments: The authors are grateful to Milena Monnier, Roberta Battistini, Lucia Florio and Claudia Palmitessa for their assistance with biomolecular, immunohistochemical and Western Blot analyses. Particular thanks are due to Walter Mignone and Enrica Berio for necropsying some of the animals for this study. A special note of thanks goes to the Department of Prevention, Local Veterinary Services (ASL 1 Imperiese) for their assistance.

Conflicts of Interest: The authors declare no conflict of interest. The funders had no role in the design of the study, in the collection, analysis or interpretation of data, in the writing of the manuscript or in the decision to publish the results.

\section{References}

1. Pintore, M.D.; Mignone, W.; Di Guardo, G.; Mazzariol, S.; Ballardini, M.; Florio, C.L.; Goria, M.; Romano, A.; Caracappa, S.; Giorda, F.; et al. Neuropathologic findings in cetaceans stranded in Italy (2002-14). J. Wildl. Dis. 2018, 54, 295-303. [CrossRef]

2. Sierra, E.; Fernández, A.; Felipe-Jiménez, I.; Zucca, D.; Díaz-Delgado, J.; Puig-Lozano, R.; Câmara, N.; Consoli, F.; Díaz-Santana, P.; Suárez-Santana, C.; et al. Histopathological Differential Diagnosis of Meningoencephalitis in Cetaceans: Morbillivirus, Herpesvirus, Toxoplasma gondii, Brucella sp., and Nasitrema sp. Front. Vet. Sci. 2020, 7, 650. [CrossRef] [PubMed]

3. Wessels, M.E.; Deaville, R.; Perkins, M.W.; Jepson, P.D.; Penrose, R.; Rocchi, M.S.; Maley, M.; Ballingall, K.T.; Dagleish, M.P. Novel Presentation of DMV-Associated Encephalitis in a Long-Finned Pilot Whale (Globicephala melas). J. Comp. Pathol. 2021, 183, 51-56. [CrossRef] [PubMed] 
4. Zinzula, L.; Mazzariol, S.; Di Guardo, G. Molecular signatures in cetacean morbillivirus and host species proteomes: Unveiling the evolutionary dynamics of an enigmatic pathogen? Microbiol. Immunol. 2021, 66, 52-58. [CrossRef]

5. Groch, K.R.; Colosio, A.C.; Marcondes, M.C.C.; Zucca, D.; Díaz-Delgado, J.; Niemeyer, C.; Marigo, J.; Brandão, P.E.; Fernández, A.; Catão-Dias, J.L. Novel cetacean morbillivirus in Guiana Dolphin, Brazil. Emerg. Infect. Dis. 2014, 20, 511-513. [CrossRef] [PubMed]

6. West, K.L.; Sanchez, S.; Rotstein, D.; Robertson, K.M.; Dennison, S.; Levine, G.; Davis, N.; Schofield, D.; Potter, C.W.; Jensen, B. A Longman's beaked whale (Indopacetus pacificus) strands in Maui, Hawaii, with first case of morbillivirus in the central Pacific. Mar. Mammal Sci. 2013, 29, 767-776. [CrossRef]

7. Stephens, N.; Duignan, P.J.; Wang, J.; Bingham, J.; Finn, H.; Bejder, L.; Patterson, I.A.P.; Holyoake, C. Cetacean morbillivirus in coastal indo-pacific bottlenose dolphins, Western Australia. Emerg. Infect. Dis. 2014, 20, 666-670. [CrossRef] [PubMed]

8. West, K.L.; Silva-Krott, I.; Landrau-Giovannetti, N.; Rotstein, D.; Saliki, J.; Raverty, S.; Nielsen, O.; Popov, V.L.; Davis, N.; Walker, W.A.; et al. Novel cetacean morbillivirus in a rare Fraser's dolphin (Lagenodelphis hosei) stranding from Maui, Hawai'i. Sci. Rep. 2021, 11, 15986. [CrossRef]

9. Peletto, S.; Caruso, C.; Cerutti, F.; Modesto, P.; Biolatti, C.; Pautasso, A.; Grattarola, C.; Giorda, F.; Mazzariol, S.; Mignone, W.; et al. Efficient isolation on Vero.DogSLAMtag cells and full genome characterization of Dolphin Morbillivirus (DMV) by next generation sequencing. Sci. Rep. 2018, 8, 860. [CrossRef]

10. Cerutti, F.; Giorda, F.; Grattarola, C.; Mignone, W.; Beltramo, C.; Keck, N.; Lorusso, A.; Di Francesco, G.; Di Renzo, L.; Di Guardo, G.; et al. Specific capture and whole-genome phylogeography of Dolphin morbillivirus. Sci. Rep. 2020, 10, 20831. [CrossRef]

11. Mira, F.; Rubio-Guerri, C.; Purpari, G.; Puleio, R.; Caracappa, G.; Gucciardi, F.; Russotto, L.; Loria, G.R.; Guercio, A. Circulation of a novel strain of dolphin morbillivirus (DMV) in stranded cetaceans in the Mediterranean Sea. Sci. Rep. 2019, 9, 9792. [CrossRef]

12. Pautasso, A.; Iulini, B.; Grattarola, C.; Giorda, F.; Goria, M.; Peletto, S.; Masoero, L.; Mignone, W.; Varello, K.; Petrella, A.; et al. Novel dolphin morbillivirus (DMV) outbreak among Mediterranean striped dolphins Stenella coeruleoalba in Italian waters. Dis. Aquat. Organ. 2019, 132, 215-220. [CrossRef]

13. Vandevelde, M.; Zurbriggen, A. Demyelination in canine distemper virus infection: A review. Acta Neuropathol. 2005, 109, 56-68. [CrossRef]

14. Ulrich, R.; Puff, C.; Wewetzer, K.; Kalkuhl, A.; Deschl, U.; Baumgärtner, W. Transcriptional changes in canine distemper virus-induced demyelinating leukoencephalitis favor a biphasic mode of demyelination. PLoS ONE 2014, 9. [CrossRef] [PubMed]

15. Mazzariol, S.; Peletto, S.; Mondin, A.; Centelleghe, C.; Di Guardo, G.; Di Francesco, C.E.; Casalone, C.; Acutis, P.L. Dolphin morbillivirus infection in a captive harbor seal (phoca vitulina). J. Clin. Microbiol. 2013, 51, 708-711. [CrossRef] [PubMed]

16. Duignan, P.J.; Van Bressem, M.F.; Baker, J.D.; Barbieri, M.; Colegrove, K.M.; de Guise, S.; de Swart, R.L.; di Guardo, G.; Dobson, A.; Duprex, W.P.; et al. Phocine distemper Virus: Current knowledge and future directions. Viruses 2014, 6, 5093-5134. [CrossRef]

17. Duignan, P.J.; Geraci, J.R.; Raga, J.A.; Calzada, N. Pathology of morbillivirus infection in striped dolphins (Stenella coeruleoalba) from Valencia and Murcia, Spain. Can. J. Vet. Res. 1992, 56, 242-248. [PubMed]

18. Domingo, M.; Vilafranca, M.; Visa, J.; Prats, N.; Trudgett, A.; Visser, I. Evidence for chronic morbillivirus infection in the Mediterranean striped dolphin (Stenella coeruleoalba). Vet. Microbiol. 1995, 44, 229-239. [CrossRef]

19. Soto, S.; Alba, A.; Ganges, L.; Vidal, E.; Raga, J.A.; Alegre, F.; González, B.; Medina, P.; Zorrilla, I.; Martínez, J.; et al. Post-epizootic chronic dolphin morbillivirus infection in Mediterranean striped dolphins Stenella coeruleoalba. Dis. Aquat. Organ. 2011, 96, 187-194. [CrossRef]

20. Díaz-Delgado, J.; Groch, K.R.; Sierra, E.; Sacchini, S.; Zucca, D.; Quesada-Canales, Ó.; Arbelo, M.; Fernández, A.; Santos, E.; Ikeda, J.; et al. Comparative histopathologic and viral immunohistochemical studies on CeMV infection among Western Mediterranean, Northeast-Central, and Southwestern Atlantic cetaceans. PLoS ONE 2019, 14, e0213363. [CrossRef]

21. Geraci, J.R.; Lounsbury, V.J.; Texas A \& M University. Sea Grant College Program. In Marine Mammals Ashore: A Field Guide for Strandings, 2nd ed.; National Aquarium in Baltimore: Baltimore, MD, USA, 2005; Volume 486, ISBN 9780977460908.

22. Carlini, R.; de Francesco, M.C.; Libera, S. Della Biometric measures indicating sexual dimorphism in Stenella coeruleoalba (Meyen, 1833) (Delphinidae) in the north-central Tyrrhenian sea. Aquat. Mamm. 2014, 40, 59-68. [CrossRef]

23. IJsseldijk, L.L.; Brownlow, A.C.; Mazzariol, S. (Eds.) Best Practice on Cetacean Post Mortem Investigation and Tissue Sampling ACCOBAMS ASCOBANS, Ed. In Proceedings of the 25th Meeting of the Advisory Committee, Stralsund, Germany, 17-19 September 2019; p. 73.

24. Hernández-Mora, G.; González-Barrientos, R.; Morales, J.A.; Chaves-Olarte, E.; Guzmán-Verri, C.; Baquero-Calvo, E.; De-Miguel, M.J.; Marín, C.M.; Blasco, J.M.; Moreno, E. Neurobrucellosis in stranded dolphins, Costa Rica. Emerg. Infect. Dis. 2008, 14, 1430-1433. [CrossRef]

25. Di Guardo, G.; Proietto, U.; Di Francesco, C.E.; Marsilio, F.; Zaccaroni, A.; Scaravelli, D.; Mignone, W.; Garibaldi, F.; Kennedy, S.; Forster, F; et al. Cerebral toxoplasmosis in striped dolphins (stenella coeruleoalba) stranded along the ligurian sea coast of Italy. Vet. Pathol. 2010, 47, 245-253. [CrossRef] [PubMed]

26. Verna, F.; Giorda, F.; Miceli, I.; Rizzo, G.; Pautasso, A.; Romano, A.; Iulini, B.; Pintore, M.D.; Mignone, W.; Grattarola, C.; et al. Detection of morbillivirus infection by RT-PCR RFLP analysis in cetaceans and carnivores. J. Virol. Methods 2017, $247,22-27$. [CrossRef] [PubMed] 
27. Grattarola, C.; Gallina, S.; Giorda, F.; Pautasso, A.; Ballardini, M.; Iulini, B.; Varello, K.; Goria, M.; Peletto, S.; Masoero, L.; et al. First report of Salmonella 1,4,[5],12:i:- in free-ranging striped dolphins (Stenella coeruleoalba), Italy. Sci. Rep. $2019,9,6061$. [CrossRef] [PubMed]

28. Garofolo, G.; Petrella, A.; Lucifora, G.; Di Francesco, G.; Di Guardo, G.; Pautasso, A.; Iulini, B.; Varello, K.; Giorda, F.; Goria, M.; et al. Occurrence of Brucella ceti in striped dolphins from Italian Seas. PLoS ONE 2020, 15, e0240178. [CrossRef] [PubMed]

29. Giorda, F.; Romani-Cremaschi, U.; Marsh, A.E.; Grattarola, C.; Iulini, B.; Pautasso, A.; Varello, K.; Berio, E.; Gazzuola, P.; Marsili, L.; et al. Evidence for Unknown Sarcocystis-Like Infection in Stranded Striped Dolphins (Stenella coeruleoalba) from the Ligurian Sea, Italy. Animals 2021, 11, 1201. [CrossRef]

30. Giorda, F.; Di Guardo, G.; Varello, K.; Pautasso, A.; Sierra, E.; Pintore, M.D.; Grattarola, C.; Colella, E.M.; Berio, E.; Goria, M.; et al. Retrospective immunohistochemical investigation on dolphin morbillivirus infection by comparing the performance of heterologous monoclonal and polyclonal antibodies-Short communication. Acta Vet. Hung. 2021, 69, 204-210. [CrossRef]

31. Alldinger, S.; Baumgärtner, W.; Örvell, C. Restricted expression of viral surface proteins in canine distemper encephalitis. Acta Neuropathol. 1993, 85, 635-645. [CrossRef]

32. Van Bressem, M.F.; Duignan, P.J.; Banyard, A.; Barbieri, M.; Colegrove, K.M.; de Guise, S.; di Guardo, G.; Dobson, A.; Domingo, M.; Fauquier, D.; et al. Cetacean morbillivirus: Current knowledge and future directions. Viruses 2014, 6, 5145-5181. [CrossRef]

33. VanDevanter, D.R.; Warrener, P.; Bennett, L.; Schultz, E.R.; Coulter, S.; Garber, R.L.; Rose, T.M. Detection and analysis of diverse herpesviral species by consensus primer PCR. J. Clin. Microbiol. 1996, 34, 1666-1671. [CrossRef]

34. Vitale, M.; Galluzzo, P.; Currò, V.; Gozdzik, K.; Schillaci, D.; Di Marco Lo Presti, V. A high sensitive nested PCR for Toxoplasma gondii detection in animal and food samples. J. Microb. Biochem. Technol. 2013, 5, 39-41. [CrossRef]

35. Bellière, E.N.; Esperón, F.; Fernández, A.; Arbelo, M.; Muñoz, M.J.; Sánchez-Vizcaíno, J.M. Phylogenetic analysis of a new Cetacean morbillivirus from a short-finned pilot whale stranded in the Canary Islands. Res. Vet. Sci. 2011, 90, 324-328. [CrossRef]

36. World Organisation for Animal Health (OIE). Manual of Diagnostic Tests and Vaccines for Terrestrial Animals, 8th ed.; World Organisation for Animal Health (OIE), Ed.; World Organisation for Animal Health: Paris, France, 2018; ISBN 978-92-95108-18-9.

37. Giorda, F.; Ballardini, M.; Di Guardo, G.; Pintore, M.D.; Grattarola, C.; Iulini, B.; Mignone, W.; Goria, M.; Serracca, L.; Varello, K.; et al. Postmortem findings in cetaceans found stranded in the pelagos sanctuary, Italy, 2007-2014. J. Wildl. Dis. 2017, 53. [CrossRef] [PubMed]

38. Rubio-Guerri, C.; Melero, M.; Esperón, F.; Bellière, E.N.; Arbelo, M.; Crespo, J.L.; Sierra, E.; García-Párraga, D.; Sánchez-Vizcaíno, J.M. Unusual striped dolphin mass mortality episode related to cetacean morbillivirus in the Spanish Mediterranean sea. BMC Vet. Res. 2013, 9, 106. [CrossRef]

39. Casalone, C.; Mazzariol, S.; Pautasso, A.; Di Guardo, G.; Di Nocera, F.; Lucifora, G.; Ligios, C.; Franco, A.; Fichi, G.; Cocumelli, C.; et al. Cetacean strandings in Italy: An unusual mortality event along the Tyrrhenian Sea coast in 2013. Dis. Aquat. Organ. 2014, 109, 81-86. [CrossRef] [PubMed]

40. C.Re.Di.Ma. Italian Diagnostic Report on Stranded Cetaceans (2016). Available online: https://www.izsplv.it/components/com_ publiccompetitions/includes/download.php?id=863:report_diagnostica_spiaggiamenti_2016.pdf (accessed on 17 December 2021).

41. C.Re.Di.Ma. Italian Diagnostic Report on Stranded Cetaceans (2017). Available online: https://www.izsplv.it/components/com_ publiccompetitions/includes/download.php?id=864:report_spiaggiamenti_2017.pdf (accessed on 17 December 2021).

42. C.Re.Di.Ma. Italian Diagnostic Report on Stranded Cetaceans (2018). Available online: https://www.izsplv.it/components/ com_publiccompetitions/includes/download.php?id=865:report-senza-tabella-2018-vers-3-ottobre-2019.pdf (accessed on 17 December 2021).

43. C.Re.Di.Ma. Italian Diagnostic Report on Stranded Cetaceans (2019). Available online: https://www.izsplv.it/components/com_ publiccompetitions/includes/download.php?id=866:report-credima-2019.pdf (accessed on 17 December 2021).

44. C.Re.Di.Ma. Italian Diagnostic Report on Stranded Cetaceans (2020). Available online: https://www.izsplv.it/components/com_ publiccompetitions/includes/download.php?id=1955:report-2020_merged.pdf (accessed on 17 December 2021).

45. Di Guardo, G.; Mazzariol, S. Cetacean Morbillivirus-Associated Pathology: Knowns and Unknowns. Front. Microbiol. 2016, 7, 112. [CrossRef]

46. Mazzariol, S.; Centelleghe, C.; Cozzi, B.; Povinelli, M.; Marcer, F.; Ferri, N.; Di Francesco, G.; Badagliacca, P.; Profeta, F.; Olivieri, V.; et al. Multidisciplinary studies on a sick-leader syndrome-associated mass stranding of sperm whales (Physeter macrocephalus) along the Adriatic coast of Italy. Sci. Rep. 2018, 8, 11577. [CrossRef] [PubMed]

47. Jo, W.K.; Osterhaus, A.D.; Ludlow, M. Transmission of morbilliviruses within and among marine mammal species. Curr. Opin. Virol. 2018, 28, 133-141. [CrossRef] [PubMed]

48. Rudd, P.A.; Cattaneo, R.; von Messling, V. Canine Distemper Virus Uses both the Anterograde and the Hematogenous Pathway for Neuroinvasion. J. Virol. 2006, 80, 9361-9370. [CrossRef]

49. Costa-Silva, S.; Sacristán, C.; Gonzales-Viera, O.; Díaz-Delgado, J.; Sánchez-Sarmiento, A.M.; Marigo, J.; Groch, K.R.; Carvalho, V.L.; Ewbank, A.C.; Colosio, A.C.; et al. Toxoplasma gondii in cetaceans of Brazil: A histopathological and immunohistochemical survey. Rev. Bras. Parasitol. Vet. 2019, 28, 395-402. [CrossRef] [PubMed]

50. Antoniassi, N.A.B.; Boabaid, F.M.; Souza, R.L.; Nakazato, L.; Pimentel, M.F.A.; Filho, J.O.X.; Pescador, C.A.; Driemeier, D.; Colodel, E.M. Granulomatous meningoencephalitis due to Toxoplasma gondii in a black-headed night monkey (Aotus nigriceps). J. Zoo Wildl. Med. 2011, 42, 118-120. [CrossRef] [PubMed] 
51. Hernández-Mora, G.; Palacios-Alfaro, J.D.; González-Barrientes, R. Wildlife reservoirs of brucellosis: Brucella in aquatic environments. Rev. Sci. Tech. 2013, 32, 89-103. [CrossRef]

52. Esperón, F.; Fernández, A.; Sánchez-Vizcaíno, J.M. Herpes simplex-like infection in a bottlenose dolphin stranded in the Canary Islands. Dis. Aquat. Organ. 2008, 81, 73-76. [CrossRef] [PubMed]

53. Van Elk, C.E.; Van De Bildt, M.W.G.; De Jong, A.A.W.; Osterhaus, A.D.M.E.; Kuiken, T. Genital herpesvirus in bottlenose dolphins (Tursiops truncatus): Cultivation, epidemiology, and associated pathology. J. Wildl. Dis. 2009, 45, 895-906. [CrossRef] [PubMed]

54. Sierra, E.; Sánchez, S.; Saliki, J.T.; Blas-Machado, U.; Arbelo, M.; Zucca, D.; Fernández, A. Retrospective study of etiologic agents associated with nonsuppurative meningoencephalitis in stranded cetaceans in the canary Islands. J. Clin. Microbiol. 2014, 52, 2390-2397. [CrossRef]

55. Vargas-Castro, I.; Melero, M.; Crespo-Picazo, J.L.; Jiménez, M.d.l.Á.; Sierra, E.; Rubio-Guerri, C.; Arbelo, M.; Fernández, A.; García-Párraga, D.; Sánchez-Vizcaíno, J.M. Systematic determination of herpesvirus in free-ranging cetaceans stranded in the western mediterranean: Tissue tropism and associated lesions. Viruses 2021, 13, 2180. [CrossRef]

56. Di Francesco, G.; Cammà, C.; Curini, V.; Mazzariol, S.; Proietto, U.; Di Francesco, C.E.; Ferri, N.; Di Provvido, A.; Di Guardo, G. Coinfection by Ureaplasma spp., Photobacterium damselae and an Actinomyces-like microorganism in a bottlenose dolphin (Tursiops truncatus) with pleuropneumonia stranded along the Adriatic coast of Italy. Res. Vet. Sci. 2016, 105, 111-114. [CrossRef]

57. Gan, L.; Mao, P.; Jiang, H.; Zhang, L.; Liu, D.; Cao, X.; Wang, Y.; Wang, Y.; Sun, H.; Huang, Y.; et al. Two Prevalent Listeria ivanovii subsp. ivanovii Clonal Strains With Different Virulence Exist in Wild Rodents and Pikas of China. Front. Vet. Sci. 2020, 7, 88. [CrossRef]

58. Disson, O.; Lecuit, M. Targeting of the central nervous system by Listeria monocytogenes. Virulence 2012, 3, 213-221. [CrossRef] [PubMed]

59. Walker, J.K.; Morgan, J.H.; McLauchlin, J.; Grant, K.A.; Shallcross, J.A. Listeria innocua isolated from a case of ovine meningoencephalitis. Vet. Microbiol. 1994, 42, 245-253. [CrossRef]

60. Rocha, P.R.D.A.; Dalmasso, A.; Grattarola, C.; Casalone, C.; Del Piero, F.; Bottero, M.T.; Capucchio, M.T. Atypical cerebral listeriosis associated with Listeria innocua in a beef bull. Res. Vet. Sci. 2013, 94, 111-114. [CrossRef] [PubMed]

61. Lucá, R.; Giacominelli-Stuffler, R.; Mazzariol, S.; Roperto, S.; Cocumelli, C.; Di Guardo, G. Neuronal and astrocytic involvement in striped dolphins (Stenella coeruleoalba) with morbilliviral encephalitis. Acta Virol. 2017, 61, 495-497. [CrossRef] [PubMed]

62. Da Fontoura Budaszewski, R.; von Messling, V. Morbillivirus experimental animal models: Measles virus pathogenesis insights from canine distemper virus. Viruses 2016, 8, 274. [CrossRef] [PubMed] 